\title{
Reward-Predictive Neural Activities in Striatal Striosome Compartments
}

\author{
[DTomohiko Yoshizawa, ${ }^{1}$ Makoto Ito, ${ }^{1,2}$ and ${ }^{\mathbb{C}}$ Kenji Doya ${ }^{1}$
}

DOI:http://dx.doi.org/10.1523/ENEURO.0367-17.2018

${ }^{1}$ Neural Computation Unit, Okinawa Institute of Science and Technology Graduate University, Onna-son, Kunigamigun, Okinawa 904-0412, Japan and ²Development Department, Progress Technologies Inc, Koto-ku, Tokyo 135-0064, Japan

\section{Visual Abstract}

\section{Reward-predictive $\mathrm{Ca}^{2+}$ signals of a striosomal neuron during a classical conditioning task}

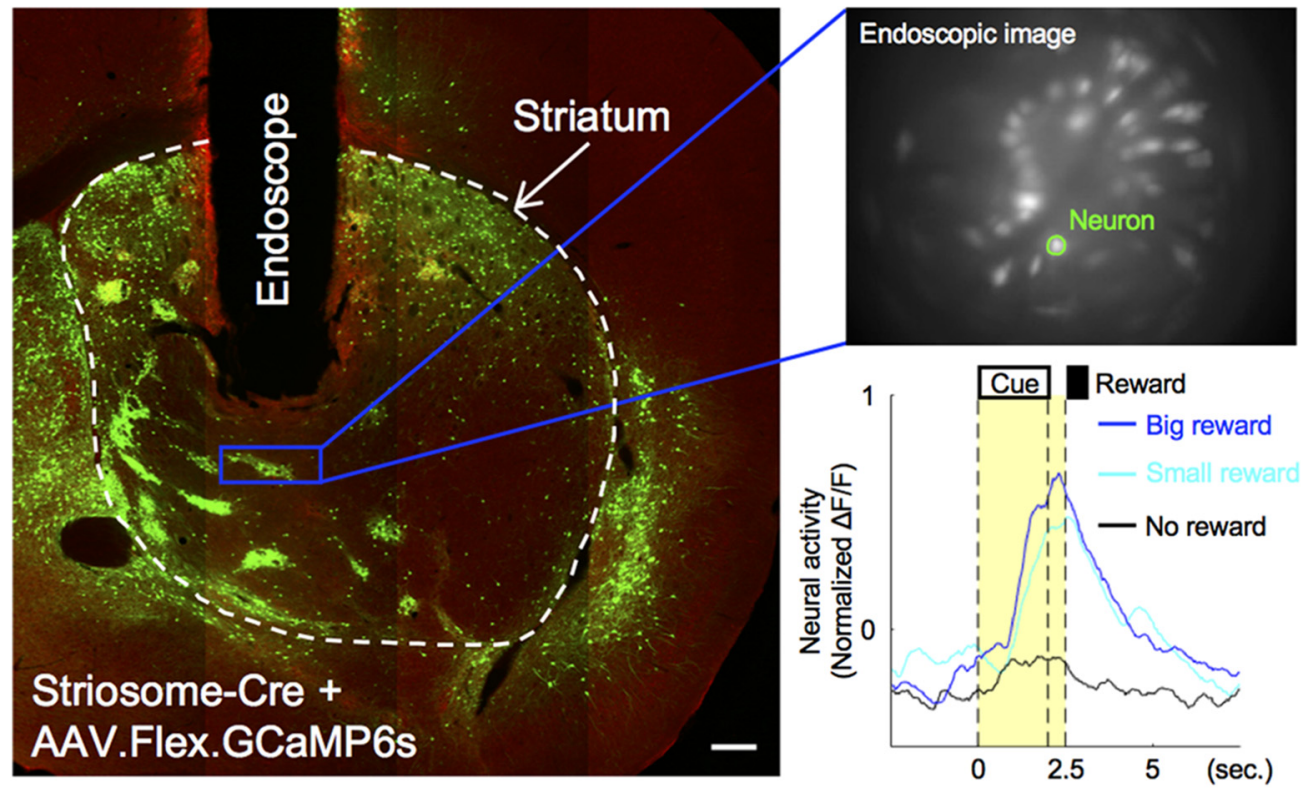

\section{Significance Statement}

Striosomes are striatal compartments that directly project to midbrain dopaminergic neurons. By using an endoscopic in vivo calcium imaging device and a striosome-Cre mouse line, we succeeded in selective recoding of striosomal neurons during a classical conditioning task and discovered reward-predictive activities proportional to the expected reward amount. Interestingly, most reward-predictive activities of striosomal neurons were observed only in early or late stage of learning. In addition, some striosomal neurons were directly activated by reward experiences. These results suggest that striosomal neurons transmit both expected and acquired reward signals to dopaminergic neurons. 
The striatum has been shown to play a critical role in reward prediction. It is composed of two neurochemically and anatomically distinct compartments known as the striosomes and the matrix. The striosomes comprise only about $15 \%$ of the striatum by volume and are distributed mosaically therein. Accordingly, it has been difficult to identify striosomal neurons in electrophysiological recordings and it has been unclear whether striosomal neurons, which project to midbrain dopaminergic neurons, engage in reward prediction. In this study, we utilized a mouse line (Sepw1-NP67) selectively expressing Cre in striosomal neurons, combined with endoscopic in vivo calcium imaging to selectively record activities of striosomal neurons during an odor-conditioning task. As mice learned the task, striosomal neurons in the dorsomedial striatum (DMS) showed predictive activities to odor cues that were associated with water rewards or aversive air puffs. These activities were proportional to the expected reward or air-puff intensity. Intriguingly, repeated recordings of the same striosomal neurons over a period of weeks revealed that predictive activities were learning-stage specific. That is, these activities disappeared after continuous training. Furthermore, presentations of rewards or air puffs activated some striosomal neurons. These findings suggest that the striosomes participate in reward prediction with learning stage-specific neural ensembles, and that they also send reward and aversive signals to dopaminergic neurons.

Key words: calcium imaging; reinforcement learning; reward; striatum; striosome; value

\section{Introduction}

The striatum consists of two neurochemically and anatomically distinct compartments: the striosomes (also known as patches), which are rich in $\mu$-opioid receptors (MORs), receive inputs from the limbic cortex, and project monosynaptically to midbrain dopaminergic neurons, and the matrix, which receives inputs from the sensorimotor and associative cortices (Jimenez-Castellanos and Graybiel, 1987; Gerfen, 1989; Eblen and Graybiel, 1995; Kincaid and Wilson, 1996). Many lines of research, including functional brain imaging (O'Doherty et al., 2004; Tanaka et al., 2004) and neural recording (Samejima et al., 2005; Ito and Doya, 2009, 2015; Kim et al., 2009) have demonstrate that the striatum plays a critical role in decisionmaking and reinforcement learning. In the process of reinforcement learning, prediction of forthcoming rewards from the present sensory state and possible actions such as "state value" and "action value," respectively, com-

Received October 26, 2017; accepted January 25, 2018; First published January 29, 2018.

The authors declare no competing financial interests.

Author contributions: T.Y., M.I., and K.D. designed research; T.Y. performed research; T.Y. analyzed data; T.Y., M.I., and K.D. wrote the paper.

This work was supported by Ministry of Education, Culture, Sports, Science and Technology KAKENHI Grants 23120007 and $16 \mathrm{H} 06563$ and by generous research support of Okinawa Institute of Science and Technology Graduate University for the Neural Computation Unit.

Acknowledgements: We thank Dr. Charles R. Gerfen (National Institute of Mental Health) for providing the Sepw1-NP67 transgenic mice line; Penn Vector Core (University of Pennsylvania) for providing AAV2/9.Syn.Flex.GCaMP6s and AAV2/9.Syn.GCaMP6s; Prof. Gordon W. Arbuthnott and the members of the Neural Computation Unit for helpful comments and discussion; and Steven D. Aird, technical editor of Okinawa Institute of Science and Technology Graduate University, for thorough editing and proofreading.

Correspondence should be addressed to either of the following: Tomohiko Yoshizawa, Neural Computation Unit, Okinawa Institute of Science and Technology Graduate University, 1919-1 Tancha, Onna-son, Kunigami-gun, Okinawa, Japan 904-0412, E-mail: tomohiko.yoshizawa@oist.jp; or Kenji Doya, Neural Computation Unit, Okinawa Institute of Science and Technology Graduate University, 1919-1 Tancha, Onna-son, Kunigami-gun, Okinawa, Japan 904-0412, E-mail: doya@oist.jp.

DOI:http://dx.doi.org/10.1523/ENEURO.0367-17.2018

Copyright @ 2018 Yoshizawa et al.

This is an open-access article distributed under the terms of the Creative Commons Attribution 4.0 International license, which permits unrestricted use, distribution and reproduction in any medium provided that the original work is properly attributed. prise the basis for learning and action selection (Sutton and Barto, 1998). These values are updated by a rewardprediction error, defined as the discrepancy between the predicted and actual rewards. The striatum is a major cortical-input site of the basal ganglia and also receives inputs from midbrain dopaminergic neurons encoding the reward-prediction error (Schultz et al., 1997). Corticostriatal synapses show dopamine-dependent plasticity that is suitable for reinforcement learning (Reynolds et al., 2001). From these observations, the striatum has been hypothesized as the brain region that predicts future rewards as state or action values (Kawagoe et al., 1998; Shidara et al., 1998; Pagnoni et al., 2002; O'Doherty et al., 2004). In fact, electrophysiological studies have shown that striatal neurons encode state or action values (Samejima et al., 2005; Pasquereau et al., 2007; Lau and Glimcher, 2008; Kim et al., 2009; Ito and Doya, 2009, 2015), but they could not identify whether recorded neurons belonged to striosomes or matrix, because these compartments form a mosaic-like structure (Pert et al., 1976; Graybiel and Ragsdale, 1978; Herkenham and Pert, 1981). Because striosomal neurons comprise only $\sim 15 \%$ of striatal neurons, it is particularly unclear whether striosomal neurons engage in reward prediction. It is important to characterize their activities during reward-based learning because almost all striatal neurons directly projecting to midbrain dopaminergic neurons belong to striosome compartments (Jiménez-Castellanos and Graybiel, 1989; Tokuno et al., 2002; Fujiyama et al., 2011; Watabe-Uchida et al., 2012).

Recently, a transgenic mouse line became available that selectively expresses Cre protein, which is a sitespecific DNA recombinase, in striosomal neurons (Gerfen et al., 2013; Smith et al., 2016). In combination with optical neural imaging, it is possible to image deep brain structures using endoscopic microscopes (Ghosh et al., 2011; Ziv et al., 2013; Resendez et al., 2016). In this study, to test whether striosomal neurons show reward-predictive activities, we recorded activities of neurons in striosomes during classical conditioning using endoscopic in vivo calcium imaging of transgenic mice with selective calcium indicator expression in their striosomal neurons. 


\section{Materials and Methods}

\section{Subjects}

Male Sepw1-NP67 (Gerfen et al., 2013) mice ( $n=8$; 25-35 g body weight; 8-12 weeks old) were housed individually under a 12/12 h light/dark cycle (lights on at 7 A.M.; off at 7 P.M.). Experiments were performed during the light phase. Water was restricted to 1-2 ml/d for two weeks before experimental initiation and during the experimental period. Food was provided ad libitum for the entire period. The Okinawa Institute of Science and Technology Graduate University Animal Research Committee approved the study.

\section{Surgery}

Mice were anesthetized with isoflurane (1.0-3.0\%) and placed in a stereotaxic frame. The skull was exposed, a hole (diameter: $1.0 \mathrm{~mm}$ ) was drilled in the skull, and the dura was removed over the imaging site. For calcium imaging, 0.4-0.6 $\mu$ l of AAV2/9.Syn.Flex.GCaMP6s $(n=5$ mice) or AAV2/9.Syn.GCaMP6s ( $n=3$, Penn Vector Core) were injected into the striatum (AP, +0.50 mm; ML, \pm 1.75 $\mathrm{mm}$; DV, $2.85 \mathrm{~mm}$ from brain surface). Three weeks after virus injection, an endoscope (GRIN lens; PartID, 130000151; diameter, $0.5 \mathrm{~mm}$; length, $6.1 \mathrm{~mm}$; Inscopix) with a custom endoscope holder was slowly implanted at the following coordinates: $\mathrm{AP},+0.50 \mathrm{~mm}$; $\mathrm{ML}, \pm 1.75 \mathrm{~mm}$; DV, $2.60 \mathrm{~mm}$. The endoscope was fixed with UV adhesive (LOCTITE 4305, Henkel) and clear dental cement (Super bond, Sun Medical) and protected by a PCR tube. A head plate (CF-10, NARISHIGE) was fixed with pink dental cement. Two to four weeks after endoscope implantation, awake mice were head-fixed with a head plate holder. A baseplate (Part ID: 100-000279; Inscopix) attached to the miniature microscope was positioned above the endoscope. The focal plane (100-300 $\mu \mathrm{m}$ working distance) was adjusted until neuronal structures and GCaMP6s responses were clearly observed. After mice were anesthetized with isoflurane, the baseplate was fixed with black-painted dental cement (CLEARFIL MAJESTY ES Flow; Kuraray Noritake Dental) and a baseplate cover (part ID: 100-000241; Inscopix) was secured to the baseplate with a set screw to protect the lens until imaging.

\section{Behavioral task}

Mice were head-fixed using the head plate and habituated for 3-5 d before task training. A custom-built olfactometer (O'Hara) delivered a 1:9 mixture of air saturated with one of four odors (isoamyl acetate, citral, eugenol, or (-)carvone) and clean air. The olfactometer constantly delivered clean air during inter-trial intervals (ITIS). ITIS were randomly selected from 10 to $20 \mathrm{~s}$. In each trial, we delivered one of four odors, selected pseudorandomly, for $2 \mathrm{~s}$, followed by a delay of $0.5 \mathrm{~s}$ and an outcome. Each odor was associated with a different outcome: a big drop of water $(4 \mu \mathrm{l})$, a small drop of water $(2 \mu \mathrm{l})$, no outcome, or an air puff delivered to the animal's face. These outcomes were randomly omitted with a $20 \%$ probability. The combination of odor and outcome differed for different mice. A daily session consisted of 100 trials. Licks were detected by interruptions of an infrared beam placed in front of the water tube. $1 \mathrm{~g}$ of water gel $\left(\mathrm{HydroGel}\right.$; $\left.\mathrm{ClearH}_{2} \mathrm{O}\right)$ was provided after daily sessions.

\section{Calcium imaging}

In each daily session, we first head-fixed mice using the head plate and holder. Then we connected the microscope to the magnetic baseplate, and fixed it in place with the baseplate set screw. Fluorescence images were acquired at $20 \mathrm{fps}$ with LED power at $20 \%$ of $1.2 \mathrm{~mW} / \mathrm{mm}^{2}$ maximum and the image sensor gain at 1.0-4.0 before A/D conversion. To compare calcium activity in different sessions, image acquisition parameters were held constant for each mouse across days. An external signal (5V TTL) from the control device triggered the start or end of recording. Neural activities in each trial were recorded from $2.5 \mathrm{~s}$ before odor onset to $5 \mathrm{~s}$ after unconditioned stimulus (US) onset (total: $10 \mathrm{~s} /$ trial) to minimize photo toxicity.

\section{Image processing}

All image processing was performed in Mosaic (version 1.1.3; Inscopix) and Matlab (version 2016b; Mathworks). First, the raw image of each frame was translated into a 16-bit tiff image. To reduce data size and processing time, spatial down-sampling (spatial binning factor: 4) was applied to each tiff image. After image sequences of all trials for each session were concatenated, a motion correction process was applied to remove movement artefacts and to compensate for shifts in microscope positioning. After removing the post-registration black borders, average fluorescence $\mathrm{F}$ was calculated over the whole motioncorrected image sequence and percentage-change-overbaseline $\left(\Delta F / F=\left(F_{n}-F\right) / F\right)$ images were generated for each frame. Here, $F_{n}$ was the motion-corrected image at $n$-th frame. Finally, $\Delta F / F$ image sequences of all sessions for each animal were concatenated, and temporally down-sampled (temporal binning factor: 4), then spatial filters to extract activities of single neurons were calculated with a cell-sorting algorithm using independent and principal component analyses (Mukamel et al., 2009).

\section{Extraction of calcium signals and event detection}

To extract calcium signals of each neuron at $20 \mathrm{~Hz}$, spatial filters were applied to the original $\Delta F / F$ image sequence of each session. The extracted calcium signal of each neuron was normalized to: mean $=0$, variance $=$ 1 (normalized $\Delta F / F$ ) for each session because the expression levels of GCaMP6s could have differed between neurons and sessions. Then, " $\mathrm{Ca}^{2+}$ events" (Okuyama et al., 2016; Kirschen et al., 2017) were detected by applying the following procedure. For the normalized $\Delta F / F$ trace in each trial $i$, all local maxima were detected and for $j$-th local maximum $\left(M_{i j}\right)$, the preceding local minimum $\left(m_{i j}\right)$ was registered. When the difference $\left(\Delta m_{i j}=M_{i j}-m_{i j}\right)$ between the local maximum and the preceding minimum exceeded a threshold $(4 \times$ the median absolute deviation, $4 \mathrm{MAD}), \Delta m_{i j}$ was registered as a $\mathrm{Ca}^{2+}$ event of amplitude $\left(y_{i k}\right)$ at the midpoint time $\left(t_{i k}\right)$ between the time of $M_{i j}$ and $m_{i j}$, where $k$ is the index of the event in a trial. 


\section{Experimental design and statistical analysis}

To show that a neuron encodes outcomes expected from odor stimuli rather than odor natures, changing of CS-US combinations between mice is effective. Therefore, we needed at least two mice each from the striosome and control groups. We actually used five and three mice from the striosome and control groups, respectively, to collect enough samples to analyze their properties.

Two-sample $t$ tests were employed for statistical tests for frequencies of licking or $\mathrm{Ca}^{2+}$ events between task conditions. To evaluate neural representations of behavioral variables, we conducted regression analyses of $\mathrm{Ca}^{2+}$ events during the CS-delay period $(2.5 \mathrm{~s}$ between CS onset and US onset) and the US period ( $2.5 \mathrm{~s}$ following US onset). Regression analysis employed the variables licking frequency (Lick), prediction of reward (Vr), air puff (Va), delivery of reward $(R w d)$, and air puff (Air). The variables $V r$ and $R w d$ took one of three levels: $0(0 \mu \mathrm{l}), 0.5(2 \mu \mathrm{l})$, and $1(4 \mu \mathrm{l})$ while Va and Air took 0 or 1 . Note that Rwd and Air took 0 in omission trials, so that they were different from $\mathrm{Vr}$ and $\mathrm{Va}$. The sum of the amplitudes of all $\mathrm{Ca}^{2+}$ events during the CS-delay or US period of $i$-th trial was registered as, $y(i, \mathrm{CS})$ and $y(i, \mathrm{US})$. First, to remove the effects of licking on neural activities, we performed the following regression analysis and obtained the residual activities $z$ :

$$
y(i, s)=\beta_{0}+\beta_{\text {Lick }} \operatorname{Lick}(i, s)+z(i, s)
$$

where $s=$ CS or US denotes the time period. We then analyzed residual activities in the CS and US periods using the following regression models.

For big, small, and no reward conditions:

$$
\begin{gathered}
z(i, \mathrm{CS})=\beta_{1}+\beta_{\mathrm{Vr}} \operatorname{Vr}(i) \\
z(i, \mathrm{US})=\beta_{2}+\beta_{\mathrm{R} w d} R w d(i)
\end{gathered}
$$

For air-puff and no reward conditions:

$$
\begin{aligned}
& z(i, \mathrm{CS})=\beta_{3}+\beta_{\mathrm{Va}} \operatorname{Va}(i) \\
& z(i, \text { US })=\beta_{4}+\beta_{\text {Air }} \operatorname{Air}(i)
\end{aligned}
$$

When the $p$ value of the regression coefficient was $<0.05$, we concluded that neural activity and the explanatory variable were significantly correlated, $\chi^{2}$ tests were used for comparison of proportions of predictive/responsive neurons between groups or stages.

For the decoding analysis, we used $n=1-10$ simultaneously recorded neurons. Since the number of simultaneously recorded neurons differed between mice, we randomly selected $n$ neurons from simultaneously recorded populations and regressed $V r$ or $V a$, and Rwd or Air with the sum of amplitudes of $\mathrm{Ca}^{2+}$ events of them during the CS-delay and US period.

For big, small, and no reward conditions:

$$
\operatorname{Vr}(i)=\mathrm{w}_{\mathrm{vr}, 0}+\sum_{j=1}^{n} \mathrm{w}_{\mathrm{vr}_{\mathrm{r}}} \mathrm{x}_{j}(i, \mathrm{CS})
$$

$$
R w d(i)=w_{\mathrm{Rwd}, 0}+\sum_{j=1}^{n} \mathrm{w}_{\mathrm{Rwd}, j} x_{j}(i, \mathrm{US})
$$

For air-puff and no reward conditions:

$$
\begin{aligned}
& \operatorname{Va}(i)=\mathrm{w}_{\mathrm{Va}, 0}+\sum_{j=1}^{n} \mathrm{w}_{\mathrm{Va}, j} x_{j}(i, \mathrm{CS}) \\
& \operatorname{Air}(i)=\mathrm{w}_{\mathrm{Air}, 0}+\sum_{j=1}^{n} \mathrm{w}_{\mathrm{Air}, j} x_{j}(i, \mathrm{US})
\end{aligned}
$$

where $x_{j}(i, \mathrm{CS})$ and $x_{j}(i, \mathrm{US})$ are the sum of amplitudes $\mathrm{Ca}^{2+}$ events during the CS-delay and US period, and $\mathrm{w}_{\mathrm{Vr}, j}, \mathrm{~W}_{\mathrm{Rwd}, j}, \mathrm{w}_{\mathrm{Va}, j}, \mathrm{w}_{\mathrm{Air}, j}$ are weights for $j$-th neuron out of $n$ neurons. After 100 iterations of these procedures for each population size $n$, we averaged MSEs of each group's mouse to compare the population coding of expected and actual US between two groups, and tested them by paired $t$ test.

\section{Immunohistochemistry}

We adapted an immunohistochemical protocol for identifying striosomes in rats (Jedynak et al., 2012) for use with mice. After all experiments were completed, mice were deeply anesthetized with pentobarbital sodium and then perfused with $4 \%$ paraformaldehyde (PFA). Brains were carefully removed so that endoscopes would not cause tissue damage, post-fixed in $4 \%$ PFA at $4^{\circ} \mathrm{C}$ overnight, and then transferred to a $30 \%$ sucrose/PBS solution at $4^{\circ} \mathrm{C}$ until brains sank to the bottom. Coronal or horizontal sections were cut at $30 \mu \mathrm{m}$ on an electrofreeze microtome (REM-710; Yamato) and stored in wells containing PBS at $4^{\circ} \mathrm{C}$. Free-floating sections were washed in PBS for $5 \mathrm{~min}$ and placed in blocking buffer $(5 \%$ normal donkey serum and $0.4 \%$ Triton $\mathrm{X}-100$ in PBS) for $2 \mathrm{~h}$ at room temperature (RT). Sections were simultaneously incubated in primary antibody-rabbit anti-MOR (ab10275; Abcam) diluted 1:500 in blocking buffer, for $48 \mathrm{~h}$ at $4^{\circ} \mathrm{C}$. Two days later, sections were washed $6 \mathrm{x}$ for $10 \mathrm{~min}$ in PBS and placed in blocking buffer for $1 \mathrm{~h}$ at RT. Sections were simultaneously incubated in secondary antibody donkey anti-rabbit (Alexa Fluor 594; Invitrogen) diluted 1:250 in blocking buffer for $2 \mathrm{~h}$ at RT. Sections were washed $6 \mathrm{x}$ for $10 \mathrm{~min}$ in PBS, mounted on glass slides and coverslipped with VECTASHIELD Mounting Medium with DAPI (Vector Laboratories). To inspect stained tissue, a confocal microscope (LSM780; Carl Zeiss) was used and pictures were taken using ZEN software.

\section{Results}

\section{Spout-licking behavior during odor conditioning}

We employed classical odor conditioning, a standard reward-based learning task for rodents (Oyama et al., 2010; Cohen et al., 2012). Water-deprived mice were classically conditioned with different odor cues predicting water (reward) or air puffs (aversive stimuli) under headrestrained conditions (Fig. 1A). Daily training sessions were composed of 100 trials. Each trial began with a conditioned stimulus (CS; odor, $2 \mathrm{~s}$ ), followed by a delay 
A

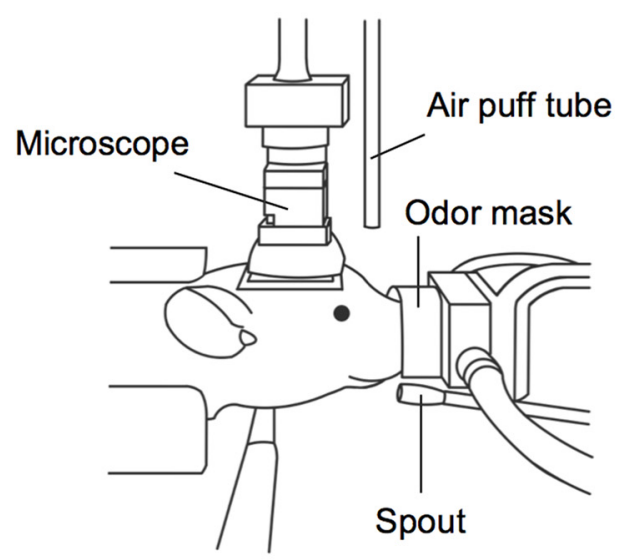

C
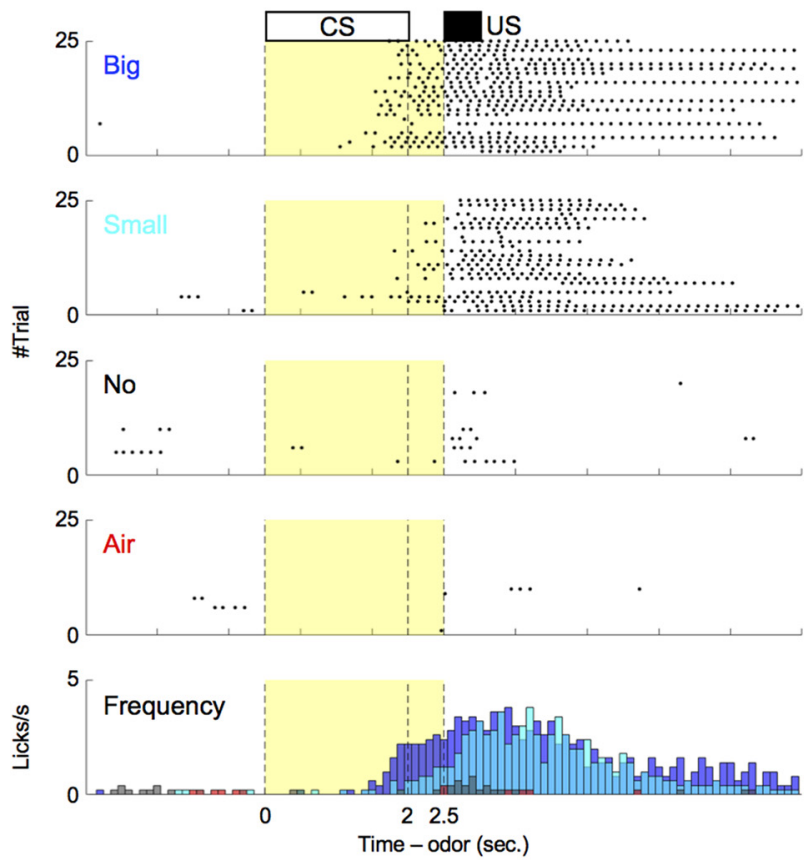

B

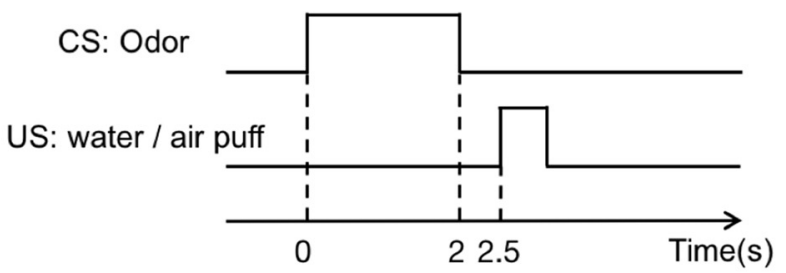

Odor A - water $4 \mu \mathrm{l}$ (Big reward)

Odor B - water $2 \mu \mathrm{l}$ (Small reward)

Odor $\mathrm{C}$ - nothing (No reward)

Odor D - air puff (Air puff)
D

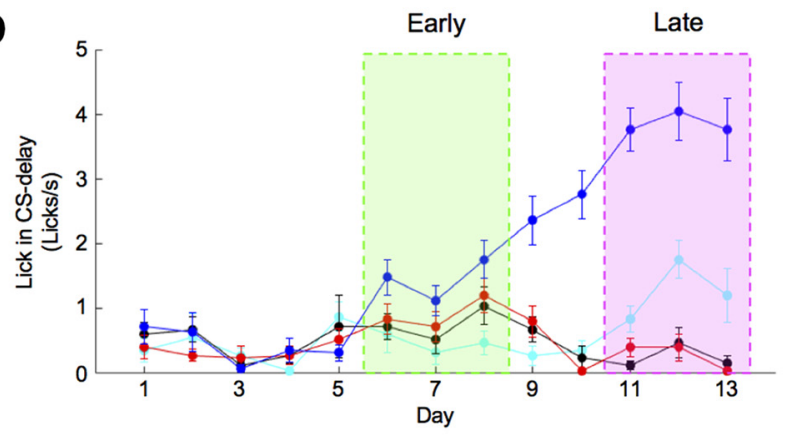

E

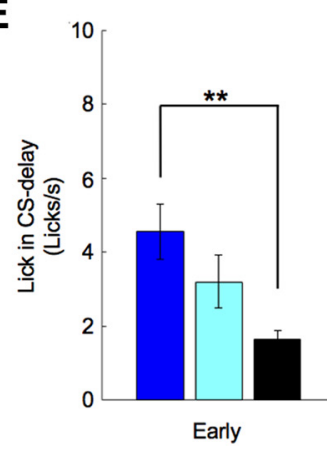

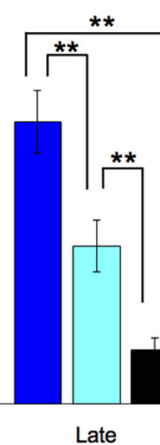

Late

Figure 1. Mice showed odor-induced reward-predictive licking behavior proportional to expected reward size. $\boldsymbol{A}$, Schematic illustration of the behavioral apparatus. Mice were restricted, head and body, by the metal frame and tube. The odor mask, water spout, and air-puff tube were set in front of their noses, mouths, and eyes. Spout-licking behaviors were monitored using an infrared sensor. The miniature microscope was mounted on their heads. $\boldsymbol{B}$, Time sequence of a classical conditioning task. $\boldsymbol{C}$, An example of reward-predictive spout-licking behaviors after sufficient learning. In trials of reward conditions, spout-licking behaviors started during odor presentation periods. Black dots indicate spout-licking behaviors. Yellow areas show CS-delay periods. $\boldsymbol{D}$, Daily changes of spout-licking frequency during CS-delay periods of the mouse illustrated in $\boldsymbol{C}$. Early and late stages were defined based on the appearance of reward-predictive licking. Error bars indicate SEs. E, Average spout-licking frequencies during CS-delay periods of all eight mice. Error bars indicate SEs.

period $(0.5 \mathrm{~s})$ and an US (water $4 \mu \mathrm{l} /$ water $2 \mu \mathrm{l} /$ air puff/ nothing; Fig. 1B). For each mouse, the CS was randomly selected from four odor cues that the mouse had to associate with different US, and the CS was fixed for all days. The combination of CS-US was varied among mice. To evaluate reward-prediction performances of the mice, we counted the number of licks toward the water-delivery spout.

In early training, mice licked the spout immediately after reward onset in some trials. After days of conditioning, they began licking during the CS-delay period before rewards arrived (Fig. 1C). To detect stages of learning, we quantified each mouse's mean daily licking frequency during the CS-delay period. Licking frequency showed no significant differences between the four odor conditions until day 5 . Then commencing at day 6 , it became significantly higher in the big-reward condition than in other conditions (Fig. 1D). By day 11, licking frequencies in big-reward, small-reward, and no-reward conditions differed significantly. Although the numbers of days for CS-US learning differed depending on the mouse, all eight mice displayed similar behavior. Therefore, we de- 
A

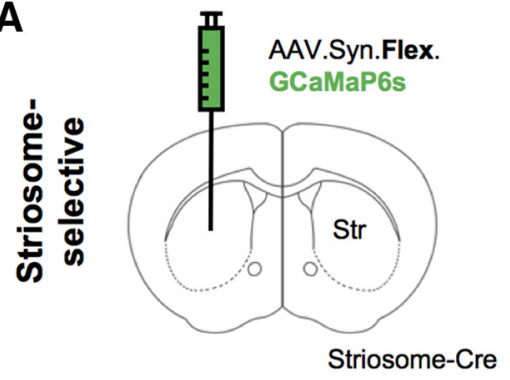

C

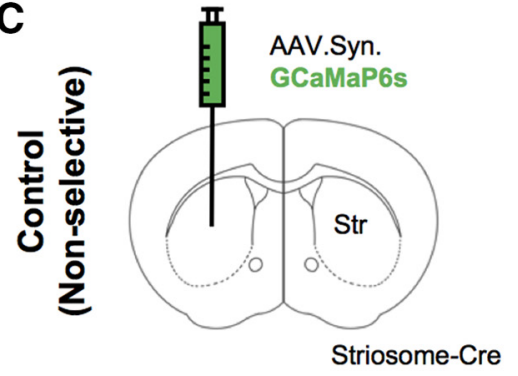

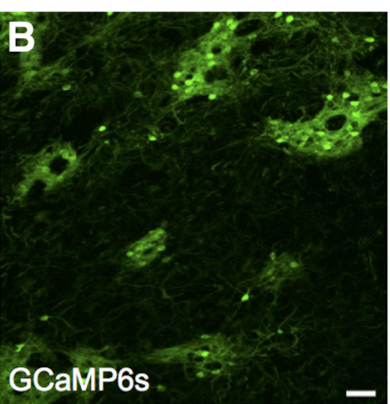
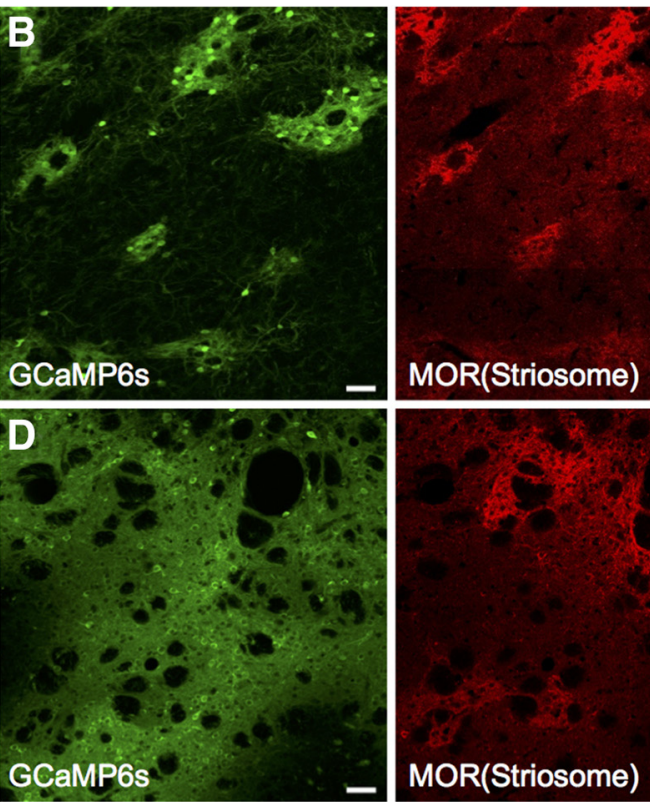
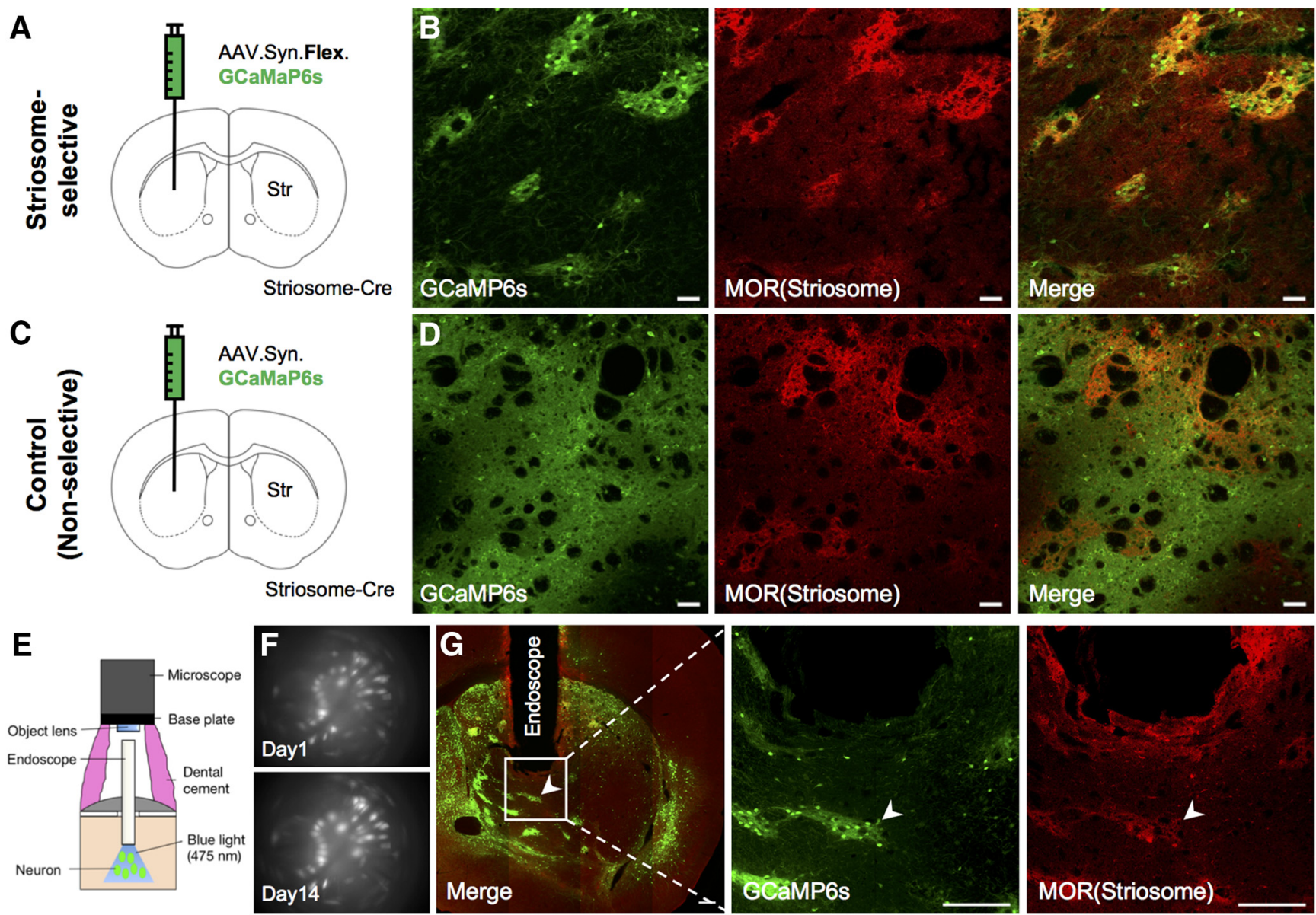

Figure 2. An endoscopic microscope was used for selective in vivo calcium imaging of striosomal neurons in the striata of Sepw1-NP67 mice expressing Cre-dependent GCaMP6s. A, Striosome group. To express GCaMP6s selectively in striosomal neurons, AAV.Syn.Flex.GCaMP6s was injected into the DMS. B, GCaMP6s (green) was selectively expressed in striosomes (red) three weeks after virus injection. Scale bar: $50 \mu \mathrm{m}$. C, Control group. To express GCaMP6s in both striosomes and matrix, AAV.Syn.GCaMP6s was injected to DMS. D, GCaMP6s expressed in both striosomes and matrix three weeks after virus injection. $\boldsymbol{E}$, Schematic illustration of endoscopic in vivo calcium imaging. $\boldsymbol{F}$, Averaged fluorescence images recorded by miniature microscope. White dots indicate neurons. The same neurons in striosomes were stably observed over two weeks. G, Images showing endoscope placement and Cre-dependent GCaMP6s-expressing neurons within the striatum. The focal plane in tissue is $250-300 \mu \mathrm{m}$ from the bottom of the endoscope, as indicated by the white arrow heads. Scale bar: $200 \mu \mathrm{m}$.

fined two learning stages: "early stage," comprising the first $3 \mathrm{~d}$ that licking frequency in the CS-delay period became significantly faster in the big-reward condition than in the no-reward condition $(p<0.05$, two-sample $t$ test), and "late stage," comprising the first $3 \mathrm{~d}$ that licking frequencies during the CS-delay period in big-reward, small-reward, and no-reward conditions all differed significantly $(p<0.05)$. The number of days from training initiation to the early stage was $4.6 \pm 0.71$ (average \pm SE) and to the late stage was $12 \pm 1.1$. Licking frequency during the CS-delay period increased monotonically with reward size in both stages (Fig. 1E). This result indicates that mice predicted forthcoming rewards from odor stimuli by learning CS-US associations.

\section{Selective in vivo calcium imaging of neurons in striosomes}

We used transgenic mice (Sepw1-NP67) expressing Cre selectively in their striosomal neurons (Gerfen et al.,
2013; Crittenden et al., 2016; Smith et al., 2016). To express GCaMP6s selectively in striosomal neurons using the Cre-loxP system, AAV2/9.Syn.Flex.GCaMP6s was injected unilaterally (left hemisphere: two mice, right hemisphere: three mice) into the dorsomedial striatum (DMS) of transgenic mice (striosome group; Fig. 2A). MOR immunohistochemistry of virus-injected brain slices confirmed that GCaMP6s was selectively expressed in striosomes (Fig. 2B). We also prepared mice expressing GCaMP6s in both striosomes and matrix as the control group by injecting AAV2/9.Syn.GCaMP6s (not containing the loxP sequences, left hemisphere: two mice, right hemisphere: one mouse) to the DMS (Fig. 2C,D).

An endoscope (GRIN lens, diameter: $0.5 \mathrm{~mm}$ ) was implanted into the DMS, and neural activities were recorded through the endoscope using a miniature microscope integrating an LED light source and an image sensor (Ghosh et al., 2011; Fig. 2E). 122 neurons were recorded from five mice in the striosome group and 83 neurons 
A
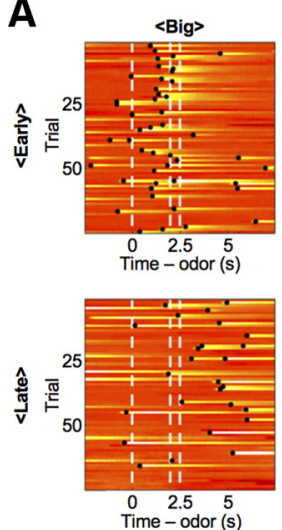

E
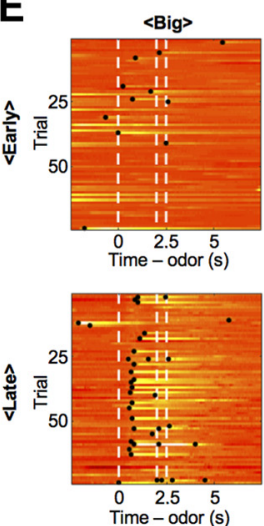
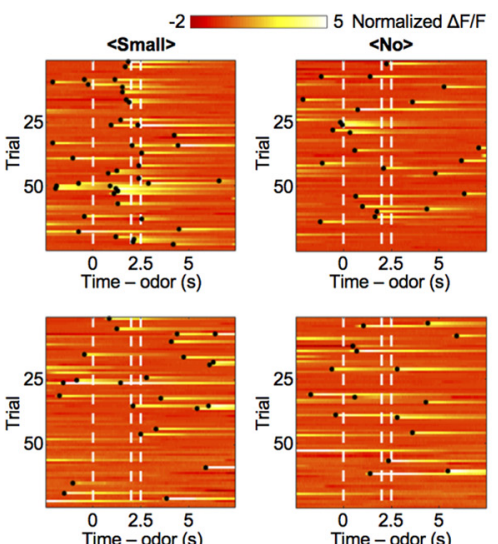

\begin{abstract}
$-3$
\end{abstract}
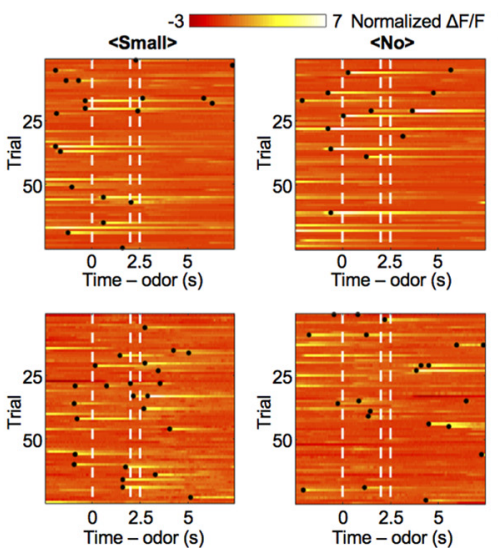
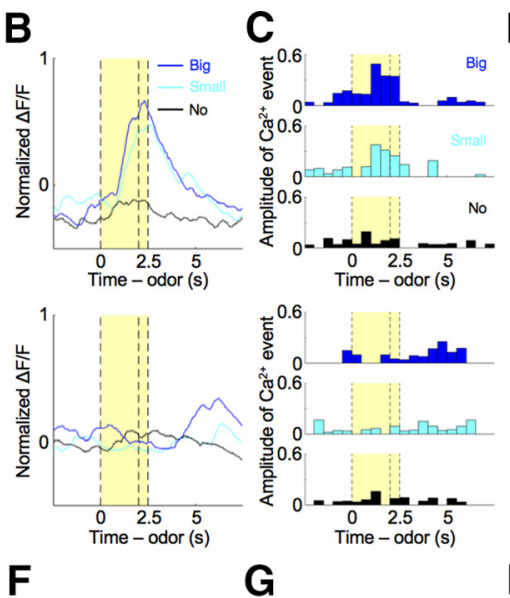

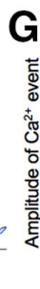
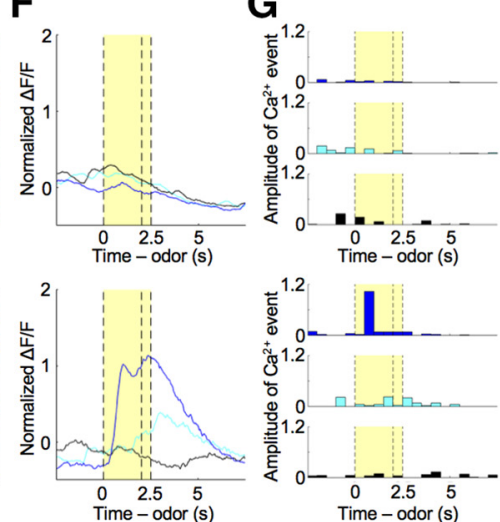

D

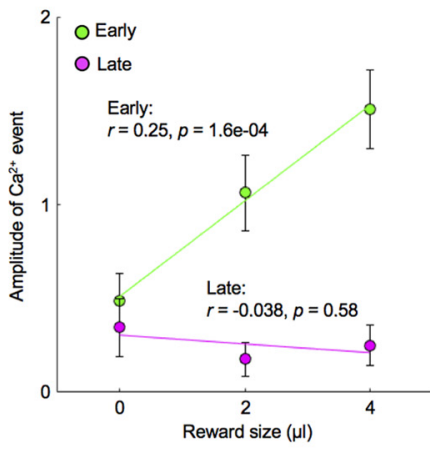

H

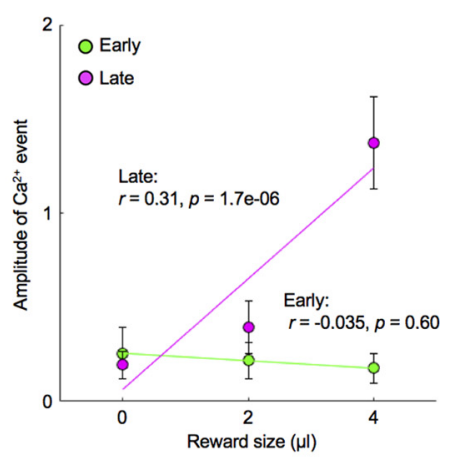

Figure 3. Reward-associated odors activated striosomal neurons in a specific learning stage. $\boldsymbol{A}$, Normalized $\Delta \mathrm{F} / \mathrm{F}$ of a striosomal neuron showing reward-predictive activity specifically in the early stage. Black dots indicate detected $\mathrm{Ca}^{2+}$ events. $\boldsymbol{B}, \boldsymbol{C}, \mathrm{Averaged}$ $\Delta \mathrm{F} / \mathrm{F}$ and $\mathrm{Ca}^{2+}$ events of the striosomal neuron illustrated in $\boldsymbol{A}$. Yellow areas show the CS-delay period. $\boldsymbol{D}$, Amplitudes of CS-delay period $\mathrm{Ca}^{2+}$ events of the striosomal neuron illustrated in $\boldsymbol{A}$ were averaged over trials and plotted against reward size. In the early stage, $\mathrm{Ca}^{2+}$ events show a positive correlation with reward size $(r=0.25, p=1.6 \mathrm{e}-04)$. On the other hand, this correlation disappeared in the late stage $(r=-0.038, p=0.58)$. Error bars and lines indicate SEs and regression lines. $\boldsymbol{E}$, Normalized $\Delta \mathrm{F} / \mathrm{F}$ of

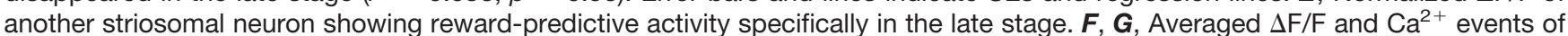
the striosomal neuron illustrated in $\boldsymbol{E}$. $\boldsymbol{H}$, Amplitudes of CS-delay period $\mathrm{Ca}^{2+}$ events of the striosomal neuron illustrated in $\boldsymbol{E}$ were averaged over trials and plotted against the reward size. In the early stage, $\mathrm{Ca}^{2+}$ events show no significant correlation with reward size $(r=-0.035, p=0.60)$. However, a positive correlation was observed in the late stage $(r=0.31, p=1.7 \mathrm{e}-06)$.

from three mice in the control group. On average, we were able to simultaneously record 24 neurons (maximum 45) from one mouse in the striosome group and 28 neurons on average (maximum 36) in the control group. Because the advantage of this imaging method is that we can continuously observe the same neurons for several weeks (Ziv et al., 2013; Resendez et al., 2016), calcium imaging was performed in all mice every day from the first to the final day of behavioral experiments (Fig. 2F). We measured fluorescence intensity of each neuron during a resting state (for $2.5 \mathrm{~s}$ before odor onset in each trial) to check changes GCaMP6s expression level. Although 7\% and $8 \%$ maximum increases in the median rate of change of fluorescence intensity were observed in the striosome and control groups, respectively, differences between sessions had no significant effect on the rate of change in either group (striosome: $p=0.69$, control: $p=0.64$, Kruskal-Wallis test). This indicates that neural activities were stably recorded throughout early and late stages.

After the imaging experiment, we made coronal brain slices including the trace of the endoscope and checked
GCaMP6s expression and MOR immunohistochemistry. In all five mice of the striosome group, we confirmed that the GCaMP6s-expressing neurons were located within the working distance of the endoscope $(250-300 \mu \mathrm{m})$ and that they were included in the MOR-positive striosome compartments (Fig. 2G).

\section{Reward-predictive neural activities}

We first examined responses of striosomal neurons to odor stimuli. After normalizing the $\Delta \mathrm{F} / \mathrm{F}$ trace of recoded neurons (normalized $\Delta \mathrm{F} / \mathrm{F}$ ), we detected $\mathrm{Ca}^{2+}$ events (Okuyama et al., 2016; Kirschen et al., 2017), which estimate the strength of neural activity while taking into account the slow decay time of GCaMP6s (Chen et al., 2013; see Materials and Methods). In the early stage, the normalized $\Delta \mathrm{F} / \mathrm{F}$ of a representative striosomal neuron (Fig. $3 A, B$ ) rose with the presentation of odor stimuli associated with the big reward, whereas no rise was observed in the no-reward condition. The sum of amplitudes of $\mathrm{Ca}^{2+}$ events during the CS-delay period in the early stage was significantly larger in the big-reward con- 
A

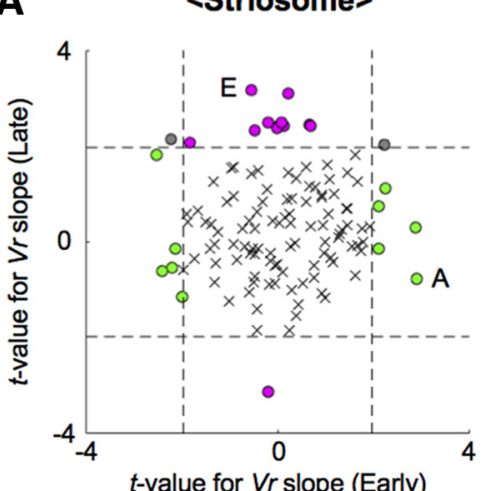

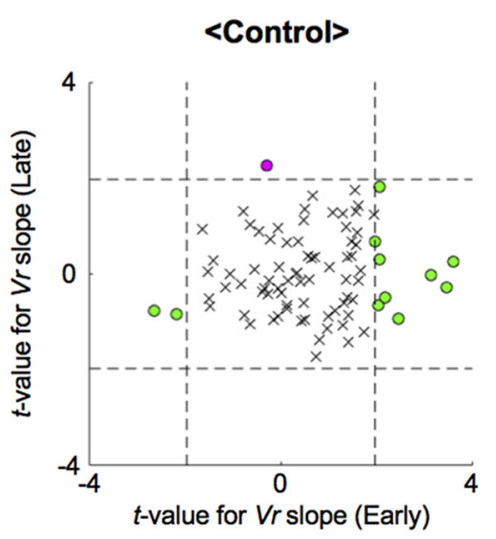

B Early specific $\square$ Both

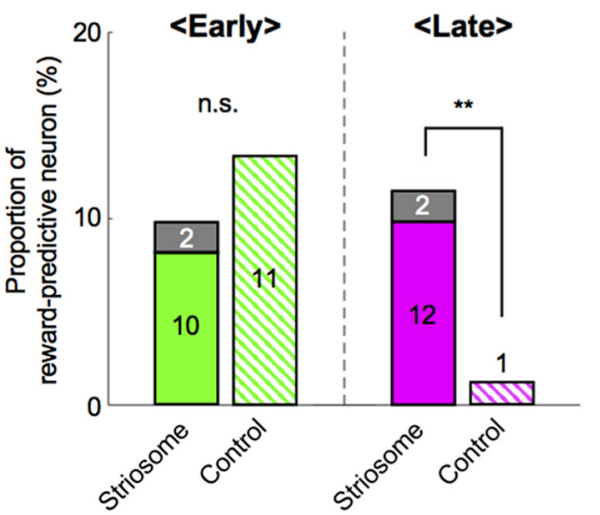

C

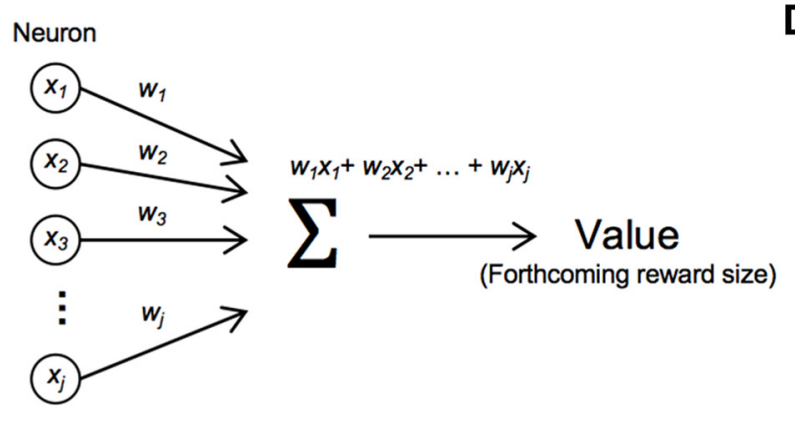

D

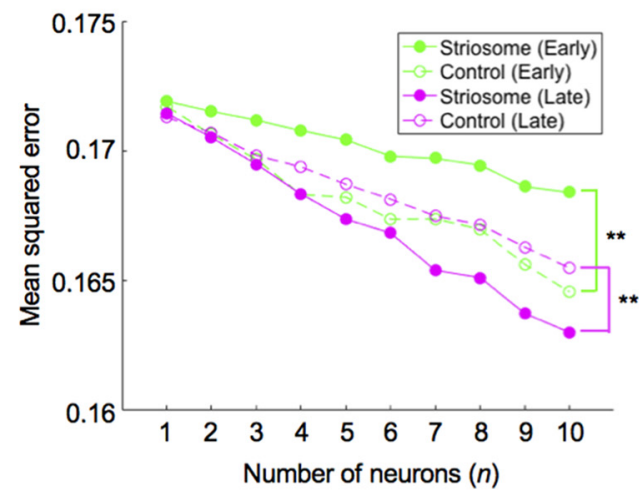

Figure 4. During each learning stage, different neural ensembles participated in reward prediction and population coding of expected reward differed between two groups. $\boldsymbol{A}$, To remove effects of motor behavior on neural activities, we first performed a regression analysis of the sum of amplitudes of $\mathrm{Ca}^{2+}$ events during the CS-delay period with frequencies of licking. Then we analyzed the residual component using prediction of reward $(V r)$. Scatter plots of t-values for regression coefficients of $V r$ in each learning stage. Dashed lines indicate levels of significant $V r$ slope at $p=0.05$. Letters $A$ and $E$ indicate the example neurons in Figure $3 A, E$. $\boldsymbol{B}$, Proportions of reward-predictive neurons in each learning stage. Numbers in bars indicate actual counts of reward-predictive neurons; $* * p<0.01$, n.s.: $p \geq 0.05, \chi^{2}$ test. $\boldsymbol{C}$, Schematic illustration of neural decoding analysis. Forthcoming reward size was estimated from the sum of weighted neuronal activities. $x_{j}$ : sum of amplitudes of $\mathrm{Ca}^{2+}$ events during the CS-delay period. $w_{j}$ : weight for $j$-th neuron out of $n$ neurons. $\boldsymbol{D}$, MSEs between actual and decoded reward sizes at each number of neurons used for analyses; $* * p<0.01$, paired $t$ test.

dition than in the no-reward condition $(p=1.2 \mathrm{e}-04$, twosample $t$ test, Fig. $3 C$ ), while the amplitude in the late stage displayed no significant difference between the big-reward condition and the no-reward condition $(p=$ 0.61 ), as the response to the odor stimulus associated with the big reward became weak. The amplitude correlated positively with forthcoming reward size in the early stage $(r=0.25, p=1.6 \mathrm{e}-04$; Fig. $3 D$ ), but not in the late stage $(r=-0.038, p=0.58)$.

In contrast, the sum of amplitudes of $\mathrm{Ca}^{2+}$ events in another striosomal neuron during the CS-delay period in the early stage showed no significant difference between the big-reward condition and the no-reward condition $(p=0.62$; Fig. $3 E-G$ ), while the response in the late stage was significantly larger in the big-reward condition $(p=$ 8.2e-06). The amplitude did not significantly correlate with forthcoming reward size in the early stage $(r=-0.035$, $p=0.60$; Fig. $3 H)$, but positively in the late stage $(r=0.31$, $p=1.7 e-06)$. Neurons in which the sum of amplitudes of $\mathrm{Ca}^{2+}$ events during the CS-delay period correlated with forthcoming reward size in one of the learning stages were found in the control group as well.

To quantify proportions of reward-predictive neurons in the striosome, we performed a regression analysis of the sum of amplitudes of $\mathrm{Ca}^{2+}$ events during the CS-delay period. To eliminate neural activities directly related to licking movements, we first conducted a regression analysis with licking frequencies and then analyzed residual components with the reward $(V r)$ predicted from the odor cues (see Materials and Methods). In most neurons of both striosome and control groups, reward-predictive activities that had significant regression coefficients to $\mathrm{Vr}$ were observed specifically in the early or the late stage (Fig. $4 A$ ); $8 \%$ of striosomal neurons (10 of 122) and $13 \%$ of control neurons (11 of 83) were reward-predictive in the early stage, but not in the late stage. On the other hand, $10 \%$ of striosomal neurons (12 of 122 ) and $1 \%$ of control neurons (1 of 83) were reward-predictive in the late stage, but not in the early stage. In the striosome group, only $2 \%$ ( 2 of 122) of the neurons were reward-predictive in both 
A
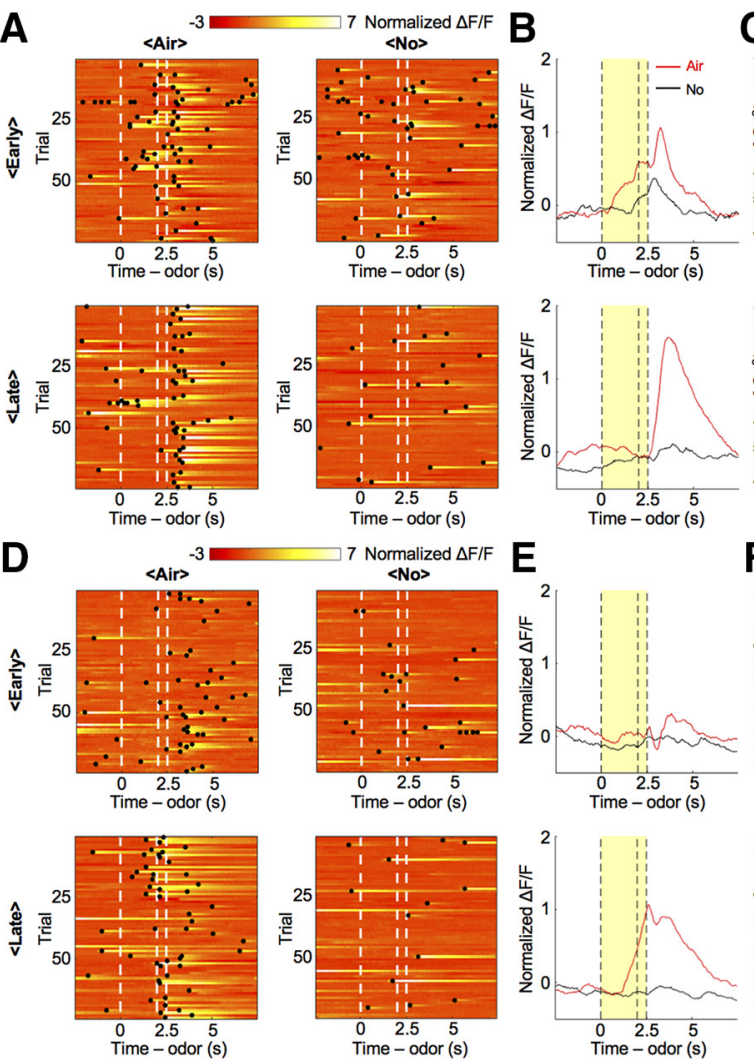
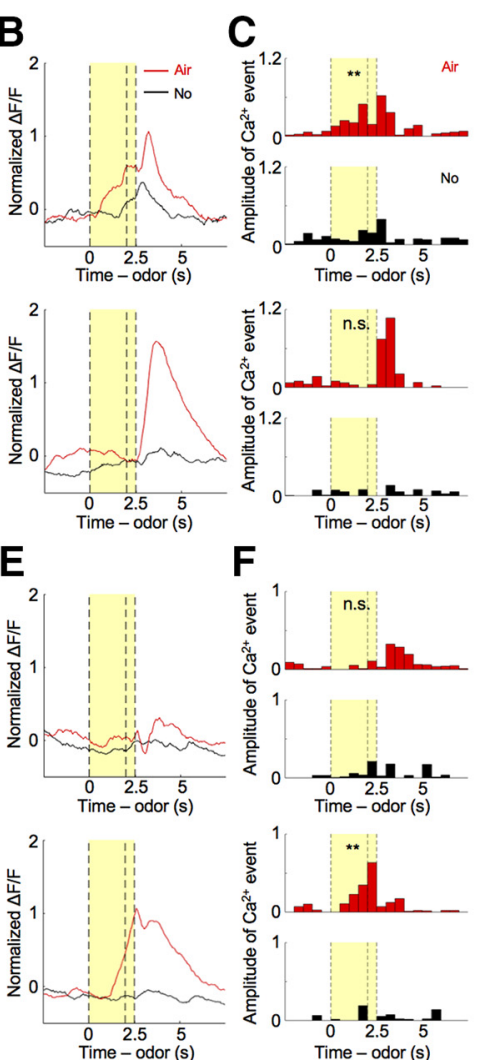

G
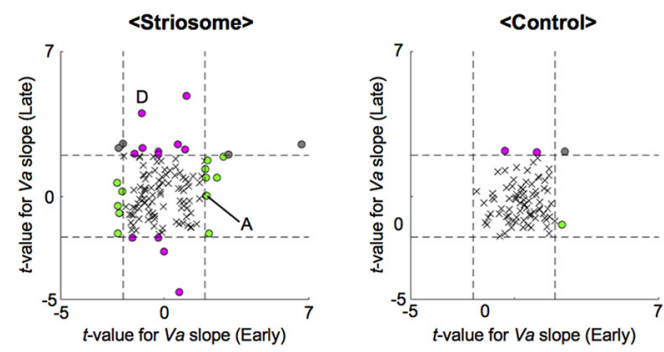

O Early specific $O$ Both $O$ Late specific $\times$ Other

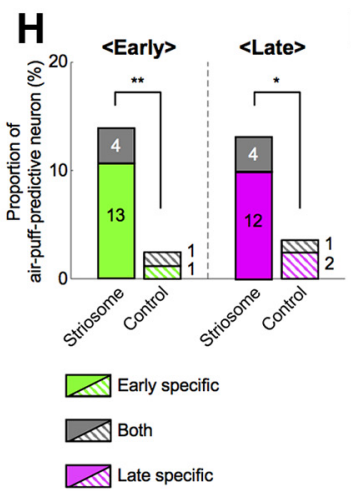

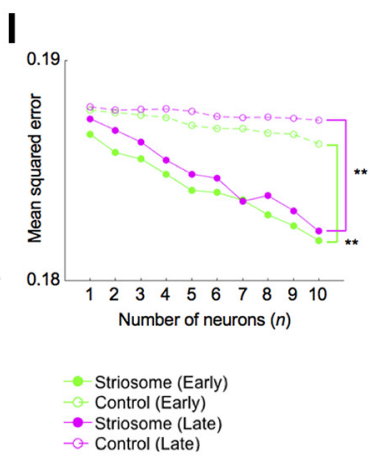

Figure 5. During each learning stage, different neural ensembles in the striosome predicted air-puff stimuli. $\boldsymbol{A}$, Normalized $\Delta \mathrm{F} / \mathrm{F}$ of a striosomal neuron showing air-puff-predictive activities specifically in the early stage. Black dots indicate detected $\mathrm{Ca}^{2+}$ events. $\boldsymbol{B}$, $\boldsymbol{C}$, Averaged $\Delta \mathrm{F} / \mathrm{F}$ and $\mathrm{Ca}^{2+}$ events of the striosomal neuron illustrated in $\boldsymbol{A}$. Yellow areas show the CS-delay period; $* * p<0.01$, n.s.: $p \geq 0.05$, two-sample $t$ test. $\boldsymbol{D}$, Normalized $\Delta \mathrm{F} / \mathrm{F}$ of another striosomal neuron showing air-puff-predictive activities specifically in the late stage. $\boldsymbol{E}, \boldsymbol{F}$, Averaged $\Delta \mathrm{F} / \mathrm{F}$ and $\mathrm{Ca}^{2+}$ events of the striosomal neuron illustrated in $\boldsymbol{D} ; * * p<0.01$, n.s.: $p \geq 0.05$. $\boldsymbol{G}$, Scatter plots of t-values for regression coefficients of prediction of air puff $(\mathrm{Va})$ in each learning stage. Dashed lines indicate levels of significant $\mathrm{Va}$ slope at $p=0.05$. Letters $A$ and $D$ indicate the example neurons in $\boldsymbol{A}, \boldsymbol{D}$. $\boldsymbol{H}$, Proportions of air-puff-predictive neurons in each learning stage. Numbers in bars indicate actual counts of air-puff-predictive neurons. $* * p<0.01, * p<0.05, \chi^{2}$ test. $\boldsymbol{I}$, MSEs between actual and decoded air-puff values at each number of neurons used for analyses; $* * p<0.01$, paired $t$ test.

learning stages. Therefore, total proportion of the striosome group was not significantly different from that of the control group, while it was larger in the late stage (early: $10 \%$, striosome, and $13 \%$, control, $p=0.45$; late: $11 \%$, striosome, and 1\%, control, $p=0.0056, \chi^{2}$ test; Fig. $4 B$ ). Compared with the early stage, reward-predictive neurons in the control group decreased in the late stage $(p=$ $0.0027)$. Moreover, the majority of reward-predictive neurons had positive regression coefficients to $\operatorname{Vr}$ (early: $50 \%$, striosome, and $82 \%$, control; late: $93 \%$, striosome, and $100 \%$, control).

Furthermore, to study neural representation of expected reward at the population level, we performed a decoding analysis of forthcoming reward size from simultaneously recorded neuronal activities. Since the numbers of simultaneously recorded neurons were different in each mouse, we randomly selected $n$ neurons from each simultaneously recorded population and used their activities during the CS-delay period for linear regression of forthcoming reward size (Fig. 4C; see Materials and Methods). We varied the subpopulation size $n$ from 1 to 10 and for each $n$, we took 100 random combinations of neurons and compared the mean squared errors (MSEs) for striosome and control groups in early and late stages (Fig. 4D). The results indicated that MSEs of the striosome group were significantly larger in the early stage and smaller in the late stage than those of the control group (early: $p=1.1 \mathrm{e}-04$, late: $p=0.0020$, paired $t$ test).

These analyses of reward-predictive neural activities revealed that neurons in striosomes represent reward values of odor stimuli in specific learning stages, and that reward-predictive striosomal neurons are more dominant in the late learning stage.

\section{Air-puff-predictive neural activities}

We next examined whether recorded neurons responded to air-puff-predictive odor stimuli. In the early stage, the normalized $\Delta F / F$ of a representative striosomal neuron (Fig. $5 A, B$ ) rose with the presentation of odor stimuli associated with an air puff, whereas this rise was not observed in the no-reward condition. The sum of amplitudes of $\mathrm{Ca}^{2+}$ events during the CS-delay period in the early stage was significantly larger in the air-puff condition than in the no-reward condition $p=0.036$, two-sample $t$ test; Fig. 5C). On the other hand, CS-delay period activity in the late stage showed no significant 
difference between the air-puff condition and the noreward condition $(p=0.98)$ as the $\Delta F / F$ response to odor stimuli associated with the air puff became weak.

Contrastingly, the sum of amplitudes of $\mathrm{Ca}^{2+}$ events in another striosomal neuron (Fig. 5D,E) during the CS-delay period in the early stage showed no significant difference between air-puff and no-reward conditions ( $p=0.35$ ), while amplitudes in the late stage were significantly larger in the air-puff condition than in the no-reward condition $(p=1.0 \mathrm{e}-04$; Fig. $5 F)$. Neurons in which the sum of amplitudes of $\mathrm{Ca}^{2+}$ events during the CS-delay period differed significantly between the air-puff and no-reward conditions in one of the learning stages were also found in the control group.

Next, we analyzed air-puff-predictive activity using the predicted delivery of an air puff $(\mathrm{Va})$ as the regressor. As in the case of reward-predictive activities, air-puff-predictive activities were observed specifically in one learning stage or the other (Fig. $5 G$ ). $11 \%$ of striosomal neurons (13 of 122 ) and $1 \%$ of control neurons (1 of 83 ) were air-puffpredictive in the early stage, but not in the late stage. On the other hand, $10 \%$ of striosomal neurons (12 of 122) and $2 \%$ of control neurons (2 of 83 ) were air-puff-predictive in the late stage, but not in the early stage. $3 \%$ of striosomal neurons (4 of 122) and 1\% of control neurons (1 of 83) were air-puff-predictive in both learning stages. This means that total proportions of the striosome group were significantly larger than those of the control group in both learning stages (early: $14 \%$, striosome, and $2 \%$, control, $p=0.0052$; late: $13 \%$, striosome, and $4 \%$, control, $p=$ $0.021, \chi^{2}$ test; Fig. $5 H$ ). Moreover, the majority of air-puffpredictive striosomal neurons had positive regression coefficients to Air (early: 58\%, striosome, and 100\%, control; late: $75 \%$, striosome, and $100 \%$, control).

Furthermore, to compare the population neural coding of expected aversive stimulus between two groups, we decoded forthcoming air-puff stimuli from the activities of various sizes of subpopulations of simultaneously recorded neurons (Fig. 5/). In both learning stages, MSEs of the striosome group were significantly smaller than those of the control group (early: $p=1.1 \mathrm{e}-05$, late: $p=2.1 \mathrm{e}-04$, paired $t$ test). These analyses of air-puff-predictive neural activities showed that neurons in striosomes also represent aversive values of odor stimuli in learning-stagespecific ways, as is the case with reward values, and suggest that aversive values are more strongly encoded in the striosomes than in the matrix.

\section{Reward- and air-puff-responsive neural activities}

The normalized $\Delta F / F$ of a representative striosomal neuron (Fig. $6 A, B$ ) rose with reward presentation, whereas that rise was not observed in the absence of a reward. The sum of amplitudes of $\mathrm{Ca}^{2+}$ events during the US period in rewarded trials was significantly larger in the big-reward condition than with no-reward $(p=1.35 \mathrm{e}-10$, two-sample $t$ test; Fig. 6C). On the other hand, amplitudes in rewardomitted trials did not differ significantly between bigreward and no-reward conditions $(p=0.25)$. Amplitude positively correlated with reward size in rewarded trials $(r=0.42, p=9.4 \mathrm{e}-10$; Fig. $6 D)$, but not in reward-omitted trials $(r=0.16, p=0.096)$. This indicates that striosomal neurons responded to the rewards themselves. Rewardresponsive activities were also observed in neurons of the control group.

After subtracting the licking component (see Materials and Methods), regression analyses of the sum of amplitudes of $\mathrm{Ca}^{2+}$ events during the US period revealed that most reward-responsive neurons, which had significant regression coefficients to the acquired reward size $R w d$, had learning-stage-specific properties, similar to those of reward-predictive neurons (Fig. 6E). A total of $13 \%$ of striosomal neurons (16 of 122) and 13\% of control neurons (11 of 83) were reward responsive in the early stage but not in the late stage. On the other hand, $11 \%$ of striosomal neurons (13 of 122) and $13 \%$ of control neurons (11 of 83) were reward responsive in the late stage, but not in the early stage; $7 \%$ of all neurons showed reward-responsive activities in both learning stages in the striosome group (9 of 122), but only $1 \%$ in the control group (1 of 83). Therefore, total proportions of the striosome group were not significantly different from those of the control group in either learning stage (early: $20 \%$, striosome, and $14 \%$, control, $p=0.27$; late: $18 \%$, striosome, and $14 \%$, control, $p=0.50, \chi^{2}$ test; Fig. $6 F$ ).

In addition, we decoded acquired reward size from various numbers of simultaneously recorded neuronal activities during the US period (Fig. 6G). In both learning stages, MSEs of the striosome group were significantly smaller than those of the control group (early: $p=0.0034$; late: $p=5.9 \mathrm{e}-04$, paired $t$ test). This decoding result also shows that the reward acquisition is more robustly presented by the striosome neurons.

The normalized $\Delta F / F$ of another striosomal neuron (Fig. $6 H, I)$ rose with the presentation of an air-puff stimulus, whereas this rise was not observed without the air puff. The sum of amplitudes of $\mathrm{Ca}^{2+}$ events during the US period was significantly larger in the air-puff condition than in the no-reward condition ( $p=1.49 \mathrm{e}-08$; Fig. 6J), whereas the response in the air-puff-omitted trials was not significantly different from that in the no-reward condition $(p=0.28)$. This indicated that the striosomal neuron respond to the air-puff stimulus itself. The air-puffresponsive activities were observed in neurons of the control group as well.

We analyzed air-puff-responsive activity using received air puff (Air) as a regressor in much the same way as with reward-responsive activities (Fig. 6K). 25\% (31 of 122) of striosomal neurons and $19 \%$ of control neurons (16 of 83) were air-puff responsive in the early stage, but not in the late stage. On the other hand, $11 \%$ of striosomal neurons (14 of 122) and $14 \%$ of control neurons (12 of 83) were air-puff responsive in the late stage, but not in the early stage. $16 \%$ of striosomal neurons (20 of 122 ) and $17 \%$ of control neurons (14 of 83) were air-puff responsive in both learning stages. This means that the two groups did not differ significantly in total proportions of air-puff-responsive neurons in either learning stage (early: $42 \%$, striosome, and $36 \%$, control, $p=0.42$; late: $28 \%$, striosome, and $31 \%$, control, $p=0.59, \chi^{2}$ test; Fig. $6 L$ ). Finally, we decoded received air-puff stimuli from various numbers of 
A
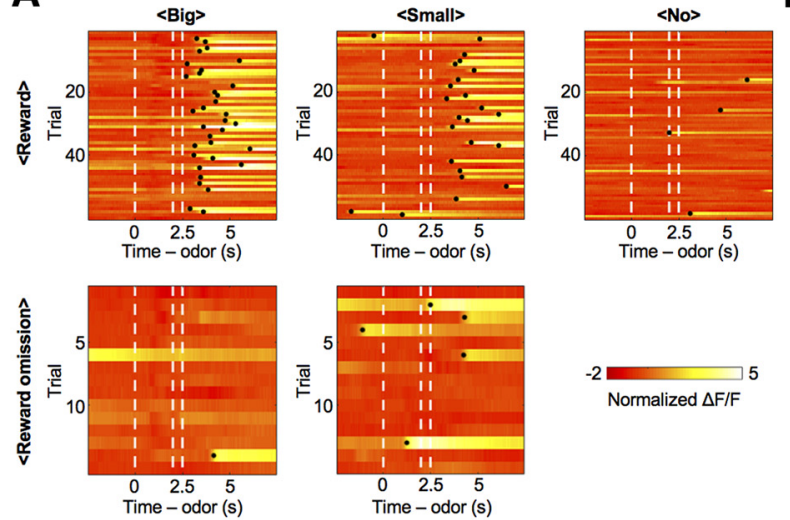

B

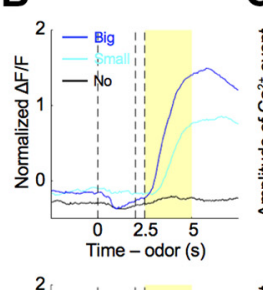

E
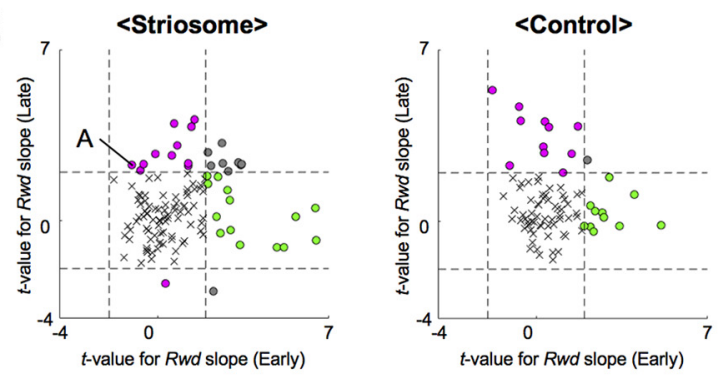

$t$-valu

Early specific $O$ Both $O$ Late specific $\times$ Other
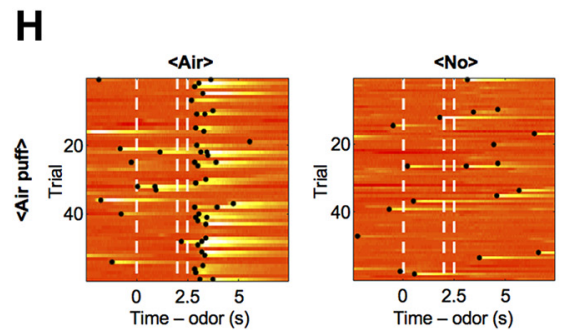

I
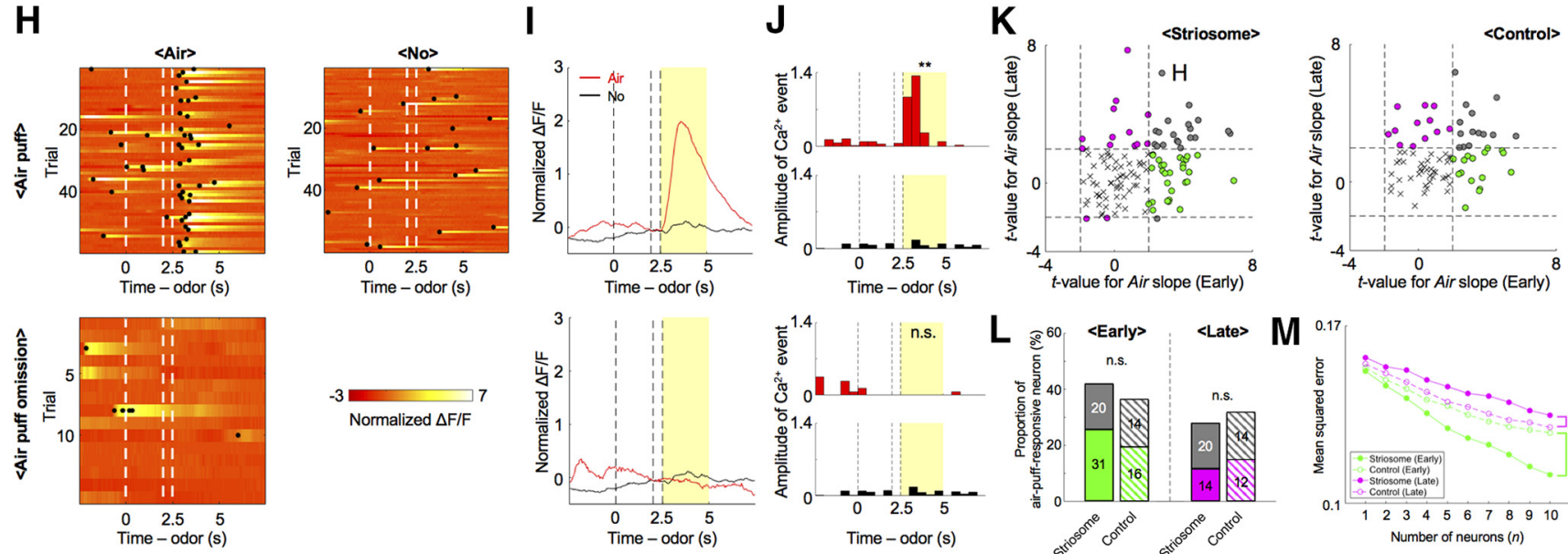

C

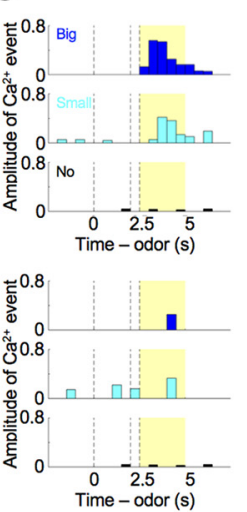

$\mathbf{F}$

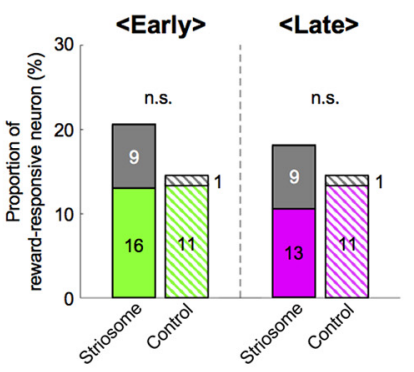

$\triangle$ Early specific $B$ Both
D

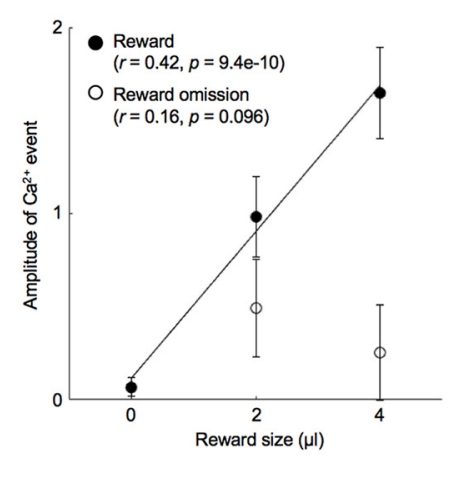

G

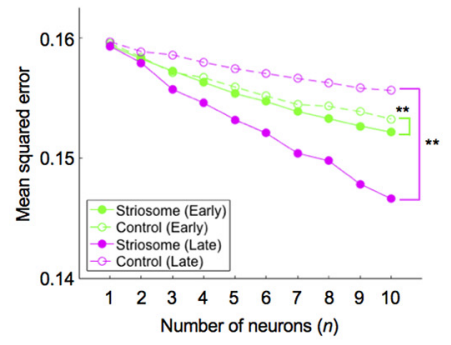

Figure 6. Both rewards and air puffs activated striosomal neurons. A, Normalized $\Delta F / F$ of a striosomal neuron showing rewardresponsive activities. This is $\Delta \mathrm{F} / \mathrm{F}$ in the late stage. Black dots indicate detected $\mathrm{Ca}^{2+}$ events. $\boldsymbol{B}, \boldsymbol{C}$, Averaged $\Delta \mathrm{F} / \mathrm{F}$ and $\mathrm{Ca}^{2+}$ events of the striosomal neuron illustrated in $\boldsymbol{A}$. Yellow areas show the US period. $\boldsymbol{D}$, Amplitudes of US period $\mathrm{Ca}^{2+}$ events of the striosomal neuron illustrated in $\boldsymbol{A}$ were averaged over trials and plotted against reward size. In rewarded trials, $\mathrm{Ca}^{2+}$ events show a positive correlation with reward size $(r=0.42, p=9.4 \mathrm{e}-10)$. On the other hand, there was no significant correlation in reward-omitted trials $(r=0.16, p=0.096)$. Error bars and lines indicate SEs and regression lines. $\boldsymbol{E}$, Scatter plots of t-values for regression coefficients of delivery of reward $(R w d)$ in each learning stage. Dashed lines indicate levels of significant $R w d$ slope at $p=0.05$. Letter $\mathrm{A}$ indicates the example neuron in $\boldsymbol{A}$. $\boldsymbol{F}$, Proportions of reward-responsive neurons in each learning stage. Numbers in bars indicate actual counts of reward-responsive neurons; n.s.: $p \geq 0.05, \chi^{2}$ test. $\mathbf{G}$, MSEs between actually received and decoded reward size at each number of neurons used for analyses; $* * p<0.01$, paired $t$ test. $\boldsymbol{H}$, Normalized $\Delta \mathrm{F} / \mathrm{F}$ of a striosomal neuron showing air-puff-responsive activities. This is also $\Delta F / F$ in the late stage. Black dots indicate detected $\mathrm{Ca}^{2+}$ events. I, $J$, Averaged $\Delta F / F$ and $\mathrm{Ca}^{2+}$ events of the striosomal neuron illustrated in $\boldsymbol{H} ; * * p<0.01$, n.s.: $p \geq 0.05$, two-sample $t$ test. $\boldsymbol{K}$, Scatter plots of $t$ values for regression coefficients of delivery of air puff (Air) in each learning stage. Dashed lines indicate levels of significant Air slope at $p=0.05$. Letter $\mathrm{H}$ indicate example neurons in $\boldsymbol{H}$. $\boldsymbol{L}$, Proportions of air-puff-responsive neurons in each learning stage. Numbers in bars indicate actual counts of air-puff-responsive neurons. n.s.: $p \geq 0.05$. $\boldsymbol{M}$, MSEs between actually received and decoded air-puff stimuli at each number of neurons used for analyses; $* * p<0.01$, paired $t$ test. 
simultaneously recorded neuronal activities during the US period (Fig. 6M). MSEs of the striosome group were significantly larger in the early stage and smaller in the late stage than those of the control group (early: $p=6.2 \mathrm{e}-04$; late: $3.2 \mathrm{e}-06$, paired $t$ test).

These results indicate that some striosomal neurons respond directly to reward or air-puff stimuli.

\section{Discussion}

We performed selective in vivo calcium imaging of neurons in striosomes and monitored neural activities of mice performing a classical odor-conditioning task. To the best of our knowledge, this is the first report to characterize striosomal neuronal activities of living animals (Note: During the final revisions of this paper, another paper on selective imaging of striosomal and matrix neurons was published (Bloem et al., 2017)). The major findings were as follows. (1) Striosomal neurons showed reward- or airpuff-predictive activities; therefore, they encoded the values of odor stimuli. (2) Most reward or air-puff-predictive activities were specific to early or late learning stages. (3) Some striosomal neurons responded to presentation of a reward or an air puff. (4) Striosomal neurons have more significant roles in reward and air-puff prediction than randomly recorded striatal neurons.

\section{Predictive neural activities in striosomes}

Although previous electrophysiological studies reported that striatal neurons represent value information (Samejima et al., 2005; Ito and Doya, 2009, 2015), they did not distinguish between striosomal and matrix neurons. In this study, we found that neurons in striosomes show rewardor air-puff-predictive activities that matched the definition of value, both by regression of single neuron activities and by decoding from population activities. We also found $\sim 10 \%$ of non-selectively recorded neurons in the DMS showed reward-predictive activities in the early stage. This proportion is consistent with a recent electrophysiological study (Ito and Doya, 2015). Since the licking frequency in cue period correlated with forthcoming reward size, it was possible that reward-predictive striosomal activity might represent motor behavior instead of reward size expected from odor stimuli. However, those activities represented the reward size even after removing the effects of licking. Thus, the striosome encodes values of odor stimuli.

This result that striosomal neurons encode values of present sensory states, supports reinforcement learning models that postulate that striosomal neurons learn state values (Barto, 1995; Doya, 2000, 2002). These models postulated that matrix neurons are involved in either action selection (actor) or action value learning. An alternative view, based on human brain imaging or lesion experiments, is that the dorsal and ventral striatum assume the roles of actor and critic, respectively (O'Doherty et al., 2004). However, the striosomes comprise a larger portion of the ventral striatum than of the dorsal striatum; whereas the matrix constitutes a smaller portion of the ventral striatum and a larger portion of the dorsal striatum (Gerfen, 1992). Therefore, the striosome-matrix difference may contribute to ventral-dorsal functional differences. A recent rabies tracing study indicated that both striosomal and matrix neurons project to dopaminergic neurons, with a higher density of SNc projecting neurons in the striosome, but a larger number in the matrix, given its larger volume (Smith et al., 2016). This new finding raises the possibility that matrix neurons are also directly involved in computation of reward prediction error signals. To test those hypotheses, we will need to record and analyze the activities of striosomal and matrix neurons during an operant conditioning task that involves choices between multiple actions. It would also be desirable to record selectively not only striosomal neurons, but also matrix neurons from the ventral, dorsomedial and dorsolateral striatum.

In both learning stages, the proportion of air-puffpredictive neurons was larger in the striosomes than in the control. Air-puff stimuli are widely used as aversive stimuli in rodents and known to cause avoidance behaviors such as predictive eye blinks (Cohen et al., 2012; Heiney et al., 2014; Piochon et al., 2014; Kloth et al., 2015). A recent study revealed anatomic connections to striosomes from the bed nucleus of the stria terminalis (Smith et al., 2016), which is known to be involved in fear or anxiety (Jennings et al., 2013; Kim et al., 2013). Furthermore, optogenetic inhibition of axon terminals of prefrontal neurons projecting to the striosomes reduced sensitivity to aversive light exposure in a cost-benefit conflict situation (Friedman et al., 2015). Air-puff-predictive neurons in striosomes might link aversive signals to avoidance behaviors through their projection to the SNr and the internal globus pallidus and fear or anxiety through their projection to the stria terminalis.

In the Sepw1-Cre mouse line used in this study, 83.2\% of Cre-expressing neurons were D1 medium spiny neurons (MSNs), projecting monosynaptically to dopaminergic neurons in the SNc, while matrix neurons that do not express Cre had no such projections (Smith et al., 2016). It was shown in the same Sepw1-Cre line that striatonigral fibers originating from the striosome form bouquet-like arborizations innervating clusters of dopamine-containing neurons with tightly bundled dendrites (Crittenden et al., 2016). Therefore, it is expected that the majority of striosomal neurons that showed reward- and air-puff-predictive activities in this study have monosynaptic projections to dopaminergic neurons in the SNc, which encode rewardprediction errors (Schultz et al., 1997). Our present discovery that the majority of reward-predictive striosomal neurons showed activities positively correlated with reward values suggests that they contribute to subtraction of predicted reward in computing reward prediction errors. On the other hand, striosomal neuronal activities that were correlated negatively with reward or positively with air puffs might contribute to computation of saliency, including both reward and aversive information, which is represented by a subset of dopaminergic neurons (Matsumoto and Hikosaka, 2009).

\section{Learning-stage-specific neural ensembles coding value information}

Since the endoscopic in vivo calcium imaging method made it possible to observe activities of the same neurons 
over long periods, we were able to compare value representations of each striatal neuron across learning stages. It was an unexpected finding that reward- or air-puffpredictive activities observed in the early stage disappeared in the late stage. It was also surprising that there were few neurons that showed reward- or air-puff-predictive activities in both early and late learning stages. This result indicates that value-coding neurons form unique ensembles depending on the learning stage. Combined with the finding of Thorn et al. (2010) that population activities of the striatum change with learning, the ensemble representation of value information in the early stage might contribute to goal-directed behavior, while that in the late stage might support habitual behavior.

\section{Differences in reward-related neural coding in striosomes and matrix}

Different parts of the striatum, especially near its ventromedial to dorsolateral axis, have different roles in goaldirected and habitual behaviors (Pennartz et al., 2009). It was reported that population activities of DMS neurons become weaker after acquisition of habitual behavior (Thorn et al., 2010). In this study, we implanted endoscopes in the DMS and monitored their neural activities during reward-based learning. Our regression analyses show that the number of reward-predictive neurons in the control group in the late stage decreased from that in the early stage. This is consistent with the result of nonselective recording of DMS neurons. In the late stage, the proportion of reward-predictive neurons was larger in the striosome group than in the control group. Our decoding analyses also showed that population neural activities of striosomes represented expected rewards more strongly than the control in the late stage. It is expected that recorded neural activities from the control group are mostly derived from the matrix, since roughly $85 \%$ of striatum neurons belong to the matrix. This suggests a possibility that striosomal neurons assume a more dominant role in reward prediction after habituation than do matrix neurons. On the other hand, roughly $80 \%$ of neurons in striosomes are D1-MSNs and another $20 \%$ are D2-MSNs, whereas the proportion is around $50 \%-50 \%$ in matrix (Fujiyama et al., 2011). Therefore, the differences between the striosome and control groups may reflect the difference in D1/D2 percentages.

Our finding of reward- and air-puff-predictive activities of neurons in striosomes contributes to understanding of mechanisms of reinforcement learning in the brain. The next important issues to clarify are whether striosomal neurons encode the state value rather than the action value in a choice task, and to test whether and how striosomal neurons contribute to computation of rewardprediction error.

\section{References}

Barto A (1995) Adaptive critics and the basal ganglia. In: Models of information processing in the basal ganglia, pp 215-232. Cambridge: MIT Press.

Bloem B, Huda R, Sur M, Graybiel AM (2017) Two-photon imaging in mice shows striosomes and matrix have overlapping but differential reinforcement-related responses. Elife 6 .
Chen TW, Wardill TJ, Sun Y, Pulver SR, Renninger SL, Baohan A, Schreiter ER, Kerr RA, Orger MB, Jayaraman V, Looger LL, Svoboda K, Kim DS (2013) Ultrasensitive fluorescent proteins for imaging neuronal activity. Nature 499:295-300. CrossRef Medline

Cohen JY, Haesler S, Vong L, Lowell BB, Uchida N (2012) Neurontype-specific signals for reward and punishment in the ventral tegmental area. Nature 482:85-88. CrossRef Medline

Crittenden JR, Tillberg PW, Riad MH, Shima Y, Gerfen CR, Curry J, Housman DE, Nelson SB, Boyden ES, Graybiel AM (2016) Striosome-dendron bouquets highlight a unique striatonigral circuit targeting dopamine-containing neurons. Proc Natl Acad Sci USA 113:11318-11323. CrossRef Medline

Doya K (2000) Complementary roles of basal ganglia and cerebellum in learning and motor control. Curr Opin Neurobiol 10:732-739. Medline

Doya K (2002) Metalearning and neuromodulation. Neural Netw 15: 495-506. CrossRef

Eblen F, Graybiel AM (1995) Highly restricted origin of prefrontal cortical inputs to striosomes in the macaque monkey. J Neurosci 15:5999-6013.

Friedman A, Homma D, Gibb LG, Amemori K, Rubin SJ, Hood AS, Riad MH, Graybiel AM (2015) A corticostriatal path targeting striosomes controls decision-making under conflict. Cell 161:13201333. CrossRef Medline

Fujiyama F, Sohn J, Nakano T, Furuta T, Nakamura KC, Matsuda W, Kaneko T (2011) Exclusive and common targets of neostriatofugal projections of rat striosome neurons: a single neuron-tracing study using a viral vector. Eur J Neurosci 33:668-677. CrossRef Medline

Gerfen CR (1989) The neostriatal mosaic: striatal patch-matrix organization is related to cortical lamination. Science 246:385-388. CrossRef

Gerfen CR (1992) The neostriatal mosaic: multiple levels of compartmental organization in the basal ganglia. Annu Rev Neurosci 15: 285-320. CrossRef Medline

Gerfen CR, Paletzki R, Heintz N (2013) GENSAT BAC crerecombinase driver lines to study the functional organization of cerebral cortical and basal ganglia circuits. Neuron 80:1368-1383. CrossRef

Ghosh KK, Burns LD, Cocker ED, Nimmerjahn A, Ziv Y, Gamal AE, Schnitzer MJ (2011) Miniaturized integration of a fluorescence microscope. Nat Methods 8:871-878. CrossRef Medline

Graybiel AM, Ragsdale CW Jr (1978) Histochemically distinct compartments in the striatum of human, monkeys, and cat demonstrated by acetylthiocholinesterase staining. Proc Natl Acad Sci USA 75:5723-5726. CrossRef

Heiney SA, Wohl MP, Chettih SN, Ruffolo LI, Medina JF (2014) Cerebellar-dependent expression of motor learning during eyeblink conditioning in head-fixed mice. J Neurosci 34:14845-14853. CrossRef

Herkenham M, Pert CB (1981) Mosaic distribution of opiate receptors, parafascicular projections and acetylcholinesterase in rat striatum. Nature 291:415-418. Medline

Ito M, Doya K (2009) Validation of decision-making models and analysis of decision variables in the rat basal ganglia. J Neurosci 29:9861-9874. CrossRef Medline

Ito M, Doya K (2015) Parallel representation of value-based and finite state-based strategies in the ventral and dorsal striatum. PLoS Comput Biol 11:e1004540. CrossRef Medline

Jedynak JP, Cameron CM, Robinson TE (2012) Repeated methamphetamine administration differentially alters fos expression in caudate-putamen patch and matrix compartments and nucleus accumbens. PLoS One 7:e34227. CrossRef Medline

Jennings JH, Sparta DR, Stamatakis AM, Ung RL, Pleil KE, Kash TL, Stuber GD (2013) Distinct extended amygdala circuits for divergent motivational states. Nature 496:224-228. CrossRef Medline

Jimenez-Castellanos J, Graybiel AM (1987) Subdivisions of the dopamine-containing A8-A9-A10 complex identified by their differential mesostriatal innervation of striosomes and extrastriosomal matrix. Neuroscience 23:223-242. Medline 
Jiménez-Castellanos J, Graybiel AM (1989) Compartmental origins of striatal efferent projections in the cat. Neuroscience 32:297321. Medline

Kawagoe R, Takikawa Y, Hikosaka O (1998) Expectation of reward modulates cognitive signals in the basal ganglia. Nat Neurosci 1:411-416. CrossRef Medline

Kim H, Sul JH, Huh N, Lee D, Jung MW (2009) Role of striatum in updating values of chosen actions. J Neurosci 29:14701-14712. CrossRef Medline

Kim S-Y, Adhikari A, Lee SY, Marshel JH, Kim CK, Mallory CS, Lo M, Pak S, Mattis J, Lim BK, Malenka RC, Warden MR, Neve R, Tye KM, Deisseroth K (2013) Diverging neural pathways assemble a behavioural state from separable features in anxiety. Nature 496: 219-223. CrossRef Medline

Kincaid AE, Wilson CJ (1996) Corticostriatal innervation of the patch and matrix in the rat neostriatum. J Comp Neur 374:578-592. CrossRef Medline

Kirschen GW, Shen J, Tian M, Schroeder B, Wang J, Man G, Wu S, Ge S (2017) Active dentate granule cells encode experience to promote the addition of adult-born hippocampal neurons. J Neurosci 37:4661-4678. CrossRef

Kloth AD, Badura A, Li A, Cherskov A, Connolly SG, Giovannucci A, Bangash MA, Grasselli G, Peñagarikano O, Piochon C, Tsai PT, Geschwind DH, Hansel C, Sahin M, Takumi T, Worley PF, Wang SS (2015) Cerebellar associative sensory learning defects in five mouse autism models. Elife 4:e06085. CrossRef Medline

Lau B, Glimcher PW (2008) Value representations in the primate striatum during matching behavior. Neuron 58:451-463. CrossRef Medline

Matsumoto M, Hikosaka O (2009) Two types of dopamine neuron distinctly convey positive and negative motivational signals. Nature 459:837-841. CrossRef Medline

Mukamel EA, Nimmerjahn A, Schnitzer MJ (2009) Automated analysis of cellular signals from large-scale calcium imaging data. Neuron 63:747-760. CrossRef Medline

O'Doherty J, Dayan P, Schultz J, Deichmann R, Friston K, Dolan RJ (2004) Dissociable roles of ventral and dorsal striatum in instrumental conditioning. Science 304:452-454.

Okuyama T, Kitamura T, Roy DS, Itohara S, Tonegawa S (2016) Ventral CA1 neurons store social memory. Science 353:15361541. CrossRef Medline

Oyama K, Hernadi I, lijima T, Tsutsui K (2010) Reward prediction error coding in dorsal striatal neurons. J Neurosci 30:1144711457. CrossRef

Pagnoni G, Zink CF, Montague PR, Berns GS (2002) Activity in human ventral striatum locked to errors of reward prediction. Nat Neurosci 5:97-98. CrossRef Medline

Pasquereau B, Nadjar A, Arkadir D, Bezard E, Goillandeau M, Bioulac B, Gross CE, Boraud T (2007) Shaping of motor responses by incentive values through the basal ganglia. J Neurosci 27:11761183. CrossRef
Pennartz CM, Berke JD, Graybiel AM, Ito R, Lansink CS, van der Meer M, Redish AD, Smith KS, Voorn P (2009) Corticostriatal interactions during learning, memory processing, and decision making. J Neurosci 29:12831-12838. CrossRef

Pert CB, Kuhar MJ, Snyder SH (1976) Opiate receptor: autoradiographic localization in rat brain. Proc Natl Acad Sci USA 73:37293733. Medline

Piochon C, Kloth AD, Grasselli G, Titley HK, Nakayama H, Hashimoto K, Wan V, Simmons DH, Eissa T, Nakatani J, Cherskov A, Miyazaki T, Watanabe M, Takumi T, Kano M, Wang SS, Hansel C (2014) Cerebellar plasticity and motor learning deficits in a copy-number variation mouse model of autism. Nat Commun 5:5586. CrossRef Resendez SL, Jennings JH, Ung RL, Namboodiri VM, Zhou ZC, Otis JM, Nomura H, McHenry JA, Kosyk O, Stuber GD (2016) Visualization of cortical, subcortical and deep brain neural circuit dynamics during naturalistic mammalian behavior with head-mounted microscopes and chronically implanted lenses. Nat Protoc 11: 566-597. CrossRef Medline

Reynolds JN, Hyland BI, Wickens JR (2001) A cellular mechanism of reward-related learning. Nature 413:67-70. CrossRef Medline

Samejima K, Ueda Y, Doya K, Kimura M (2005) Representation of action-specific reward values in the striatum. Science 310:13371340. CrossRef Medline

Schultz W, Dayan P, Montague PR (1997) A neural substrate of prediction and reward. Science 275:1593-1599. Medline

Shidara M, Aigner TG, Richmond BJ (1998) Neuronal signals in the monkey ventral striatum related to progress through a predictable series of trials. J Neurosci 18:2613-2625.

Smith JB, Klug JR, Ross DL, Howard CD, Hollon NG, Ko VI, Hoffman H, Callaway EM, Gerfen CR, Jin X (2016) Genetic-based dissection unveils the inputs and outputs of striatal patch and matrix compartments. Neuron 91:1069-1084. CrossRef Medline

Sutton RS, Barto AG (1998) Reinforcement learning. Cambridge: MIT Press.

Tanaka SC, Doya K, Okada G, Ueda K, Okamoto Y, Yamawaki S (2004) Prediction of immediate and future rewards differentially recruits cortico-basal ganglia loops. Nat Neurosci 7:887-893. CrossRef Medline

Thorn CA, Atallah H, Howe M, Graybiel AM (2010) Differential dynamics of activity changes in dorsolateral and dorsomedial striatal loops during learning. Neuron 66:781-795. CrossRef Medline

Tokuno H, Chiken S, Kametani K, Moriizumi T (2002) Efferent projections from the striatal patch compartment: anterograde degeneration after selective ablation of neurons expressing mu-opioid receptor in rats. Neurosci Lett 332:5-8. Medline

Watabe-Uchida M, Zhu L, Ogawa SK, Vamanrao A, Uchida N (2012) Whole-brain mapping of direct inputs to midbrain dopamine neurons. Neuron 74:858-873.

Ziv Y, Burns LD, Cocker ED, Hamel EO, Ghosh KK, Kitch LJ, El Gamal A, Schnitzer MJ (2013) Long-term dynamics of CA1 hippocampal place codes. Nat Neurosci 16:264-266. CrossRef Medline 